\title{
Interaction between the C-terminal region of human myelin basic protein and calmodulin: analysis of complex formation and solution
} structure

\author{
Viivi Majava1, Maxim V Petoukhov ${ }^{2,3}$, Nobuhiro Hayashi4 ${ }^{4}$, Päivi Pirilä1, \\ Dmitri I Svergun ${ }^{2,3}$ and Petri Kursula*1
}

\begin{abstract}
Address: ${ }^{1}$ Department of Biochemistry, University of Oulu, Oulu, Finland, ${ }^{2}$ EMBL Hamburg Outstation, Hamburg, Germany, ${ }^{3}$ Institute of Crystallography, Russian Academy of Sciences, Moscow, Russia and ${ }^{4}$ Institute for Comprehensive Medical Science, Fujita Health University, Japan

Email: Viivi Majava - viivi.majava@oulu.fi; Maxim V Petoukhov - maxim@embl-hamburg.de; Nobuhiro Hayashi - nhayashi@fujita-hu.ac.jp; Päivi Pirilä - paivi.pirila@oulu.fi; Dmitri I Svergun - dmitri@embl-hamburg.de; Petri Kursula* - petri.kursula@oulu.fi

* Corresponding author
\end{abstract}

Published: 19 February 2008

BMC Structural Biology 2008, 8:10 doi:10.1186/1472-6807-8-10

This article is available from: http://www.biomedcentral.com/1472-6807/8/10

(C) 2008 Majava et al; licensee BioMed Central Ltd.

This is an Open Access article distributed under the terms of the Creative Commons Attribution License (http://creativecommons.org/licenses/by/2.0), which permits unrestricted use, distribution, and reproduction in any medium, provided the original work is properly cited.

\begin{abstract}
Background: The myelin sheath is a multilamellar membrane structure wrapped around the axon, enabling the saltatory conduction of nerve impulses in vertebrates. Myelin basic protein, one of the most abundant myelin-specific proteins, is an intrinsically disordered protein that has been shown to bind calmodulin. In this study, we focus on a 19-mer synthetic peptide from the predicted calmodulin-binding segment near the C-terminus of human myelin basic protein.
\end{abstract}

Results: The interaction of native human myelin basic protein with calmodulin was confirmed by affinity chromatography. The binding of the myelin basic protein peptide to calmodulin was tested with isothermal titration calorimetry (ITC) in different temperatures, and $K_{d}$ was observed to be in the low $\mu M$ range, as previously observed for full-length myelin basic protein. Surface plasmon resonance showed that the peptide bound to calmodulin, and binding was accompanied by a conformational change; furthermore, gel filtration chromatography indicated a decrease in the hydrodynamic radius of calmodulin in the presence of the peptide. NMR spectroscopy was used to map the binding area to reside mainly within the hydrophobic pocket of the C-terminal lobe of calmodulin. The solution structure obtained by small-angle X-ray scattering indicates binding of the myelin basic protein peptide into the interlobal groove of calmodulin, while calmodulin remains in an extended conformation.

Conclusion: Taken together, our results give a detailed structural insight into the interaction of calmodulin with a C-terminal segment of a major myelin protein, the myelin basic protein. The used 19-mer peptide interacts mainly with the C-terminal lobe of calmodulin, and a conformational change accompanies binding, suggesting a novel mode of calmodulin-target protein interaction. Calmodulin does not collapse and wrap around the peptide tightly; instead, it remains in an extended conformation in the solution structure. The observed affinity can be physiologically relevant, given the high abundance of both binding partners in the nervous system. 


\section{Background}

The myelin sheath is a tightly packed multilamellar membrane structure crucial for the correct functioning of the vertebrate nervous system. Myelin carries a specific set of proteins, whose expression is tightly regulated during development. Biochemically, the composition of myelin in the central and peripheral nervous system (CNS and PNS, respectively) is different from each other [1]. Mutations in myelin proteins or an autoimmune attack towards them can lead to devastating neurological diseases.

One of the most abundant proteins of myelin is the myelin basic protein (MBP) $[2,3]$. MBP is a protein family, of which the $18.5-\mathrm{kDa}$ isoform predominates in adult myelin $[2,4]$. In CNS myelin, it comprises $30 \%$ of the total protein; it is also present in PNS myelin [5]. MBP is thought to be involved in the tight association of the cytoplasmic leaflets of apposing myelin membranes within compact myelin, where there is little, if any, cytoplasm present [6]. Several segments of MBP are target autoantigens that have been characterised in multiple sclerosis [7].

A bewildering amount of post-translational modifications, in addition to extensive alternative splicing, have been observed for MBP, leading to a number of size and charge isoforms [2]. MBP has also been characterised as being intrinsically unstructured, with a possibility of local folding, especially upon binding to ligands [3]. A low-resolution 3-dimensional model for MBP adsorbed to a lipid monolayer has been built based on electron microscopy $[8,9]$. Solution scattering experiments have also indicated an unfolded structure for lipid-free MBP; in the lipidbound state, however, the protein seems compact but not globular [10].

Several interaction partners for MBP have been characterised, including actin [11-13], tubulin [14,15], and calmodulin (CaM) [11,16-23]. Although the interaction between MBP and CaM was initially reported already in 1980 [17], relatively little structural information is available about the interaction [22]. In addition, MBP seems to have multiple regions capable of binding CaM [21,22], and it is not fully clear which of the CaM-binding sites are of physiological relevance. Some assays have also indicated a heterogeneous mode for the interaction $[20,21]$, and the interaction is affected by MBP post-translational modifications, such as citrullination $[20-22,24]$. The main CaM-binding site has been suggested to reside in the Cterminal region of CaM, between residues 132-167 $[20,21]$. At least one more site lies in the central/N-terminal region of MBP [20-22].

In the present study, we have used a synthetic peptide from the predicted CaM-binding segment near the C-ter- minus of human MBP to study the MBP-CaM interaction. We have used a number of biochemical and biophysical methods to confirm the interaction, thus accurately mapping the binding site of the peptide in CaM, and to obtain thermodynamic and structural data regarding complex formation in solution.

\section{Results \\ Native human brain MBP binds to CaM}

Affinity chromatography on CaM-sepharose was used to investigate the binding of human brain native MBP by $\mathrm{CaM}$. The results clearly indicated that in the presence of calcium ions, MBP is retained in the affinity matrix, and that upon complexation of calcium by using EGTA, MBP is released (Figure 1A). Thus, the interaction is calciumdependent, as earlier shown for bovine, murine, and human brain MBP [17-20]. Mass spectroscopic analysis indicated that the main human adult MBP isoforms, 17.2 and $18.5 \mathrm{kDa}$, were both present in the EGTA eluate, indicating that neither one of them is deficient in binding CaM (Additional file 1). Both in gel electrophoresis and mass spectroscopy, the 18.5 -kDa isoform was more abundant.

\section{Selection of a putative CaM-binding peptide}

Previously, a region near the C-terminus of MBP has been suggested to be its major CaM-binding site $[20,21]$. We used a number of sequence analysis methods to select a peptide from this region that would be expected to bind CaM with high affinity. A combination of the following parameters was used: predicted propensity to fold into a helix, a low score in disorder predictions, the presence of a putative CaM-binding site according to the CaM target database [25], and detectable sequence homology to other well-characterised CaM targets. In addition, a search for putative functionally flexible regions was carried out using Wiggle. The results of these analyses are shown in Figure 1.

The peptide HKGFKGVDAQGTLSKIFKL, corresponding to residues 138-156 of human 18.5-kDa MBP, was selected for the experiments. In brief, this is one of the two regions recognised as putative CaM targets by the CaM target database, and clearly one of the few regions in MBP that are consistently not predicted to be disordered by various disorder prediction algorithms. It is also predicted to be able to fold into an $\alpha$-helix.

\section{Conformational analysis by circular dichroism spectroscopy}

Circular dichroism (CD) experiments were performed to compare the secondary structure, folding, and thermal stability of CaM in the presence and absence of the MBP peptide. The CD spectrum of CaM alone showed a shape typical of $\alpha$-helical proteins, with negative minima at 206 
A

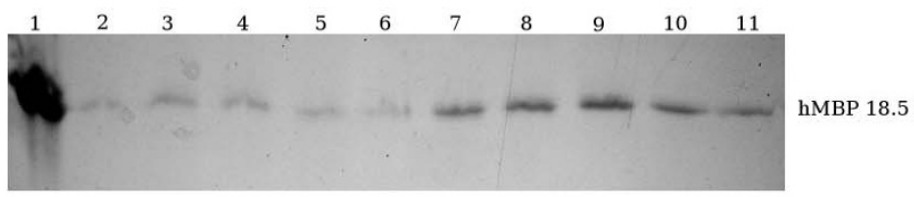

B
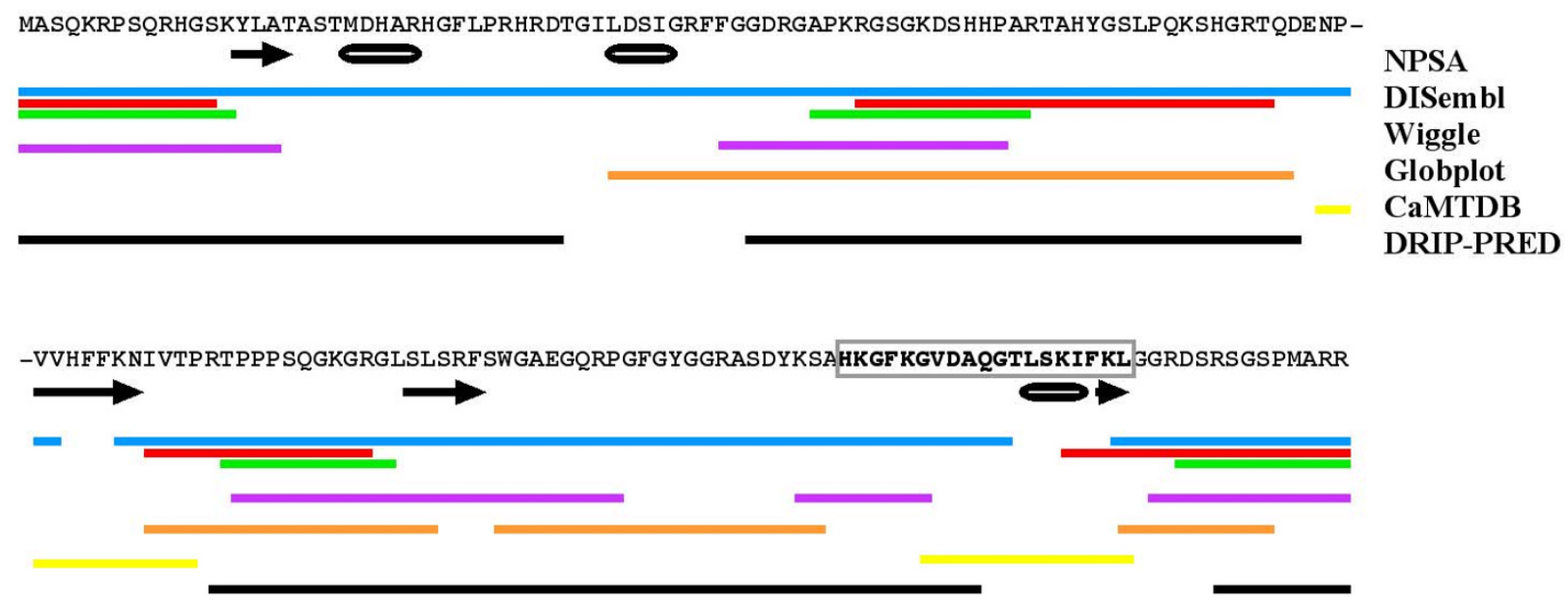

C

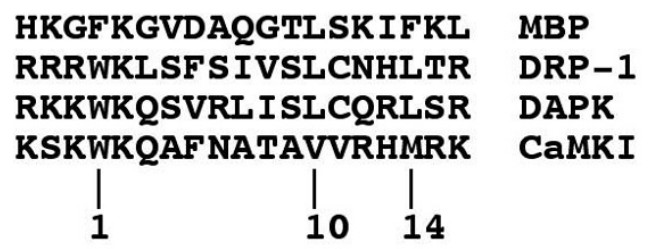

Figure I

Interaction between human brain MBP and CaM and selection of the peptide for the CaM interaction study. A. Electrophoretic analysis by SDS-PAGE of the fractions from affinity chromatography of human brain MBP on CaM-sepharose. The samples are as follows: I, adult human brain MBP isoforms loaded into the column; 2-6, washes with a buffer containing 50 $\mathrm{mM}$ HEPES $\mathrm{pH} 7.5,150 \mathrm{mM} \mathrm{NaCl}$, and $2 \mathrm{mM} \mathrm{CaCl}_{2}$; 7-II, elution with a buffer containing $50 \mathrm{mM} \mathrm{HEPES} \mathrm{pH} 7.5$, I50 mM $\mathrm{NaCl}$, and $2 \mathrm{mM} \mathrm{EGTA}$. The observed strong protein band corresponds to the I8.5-kDa main human MBP isoform. The presence of also the 17.2-kDa isoform in both the second wash (lane 3) and the second EGTA eluate (lane 8 ) was confirmed by mass spectrometry (see Additional file I). B. The sequence of human I8.5-kDa MBP, in which the bold, boxed region is the peptide eventually selected. Below the sequence, various results from sequence analysis are shown: NPSA secondary structure prediction, black arrows (helix) and cylinders (strand); DISembl disorder prediction using the 3 different learning sets in the program, blue-red-green; Wiggle prediction for functionally flexible regions, magenta; GlobPlot prediction of disorder, orange; suggested CaM-binding sites according to the CaM target database, yellow; DRIP-PRED disorder prediction, black. C. Manual alignment of the selected peptide with CaM-binding segments from three human CaM-dependent protein kinases. The positions of the conserved hydrophobic anchor residues in CaM-dependent kinases are indicated below the alignment.

and $221 \mathrm{~nm}$ and a positive maximum at $196 \mathrm{~nm}$ (Figure 2A). The CD spectrum of the complex was only slightly different from the spectrum of CaM, indicating that no major conformational changes take place upon complex formation. The k2d program [26] was used to predict the secondary structure contents (Table 1 ). The proportional content of $\alpha$-helix was somewhat smaller in the complex than in CaM, reflecting the observation that the peptide in the absence of CaM contained no $\alpha$-helix under the employed conditions (Table 1). While the fitting method 


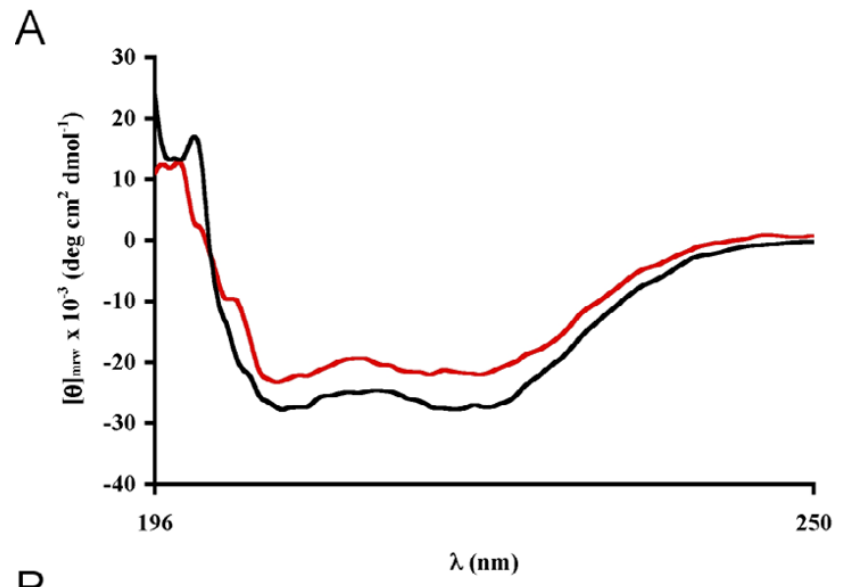

$\mathrm{B}$

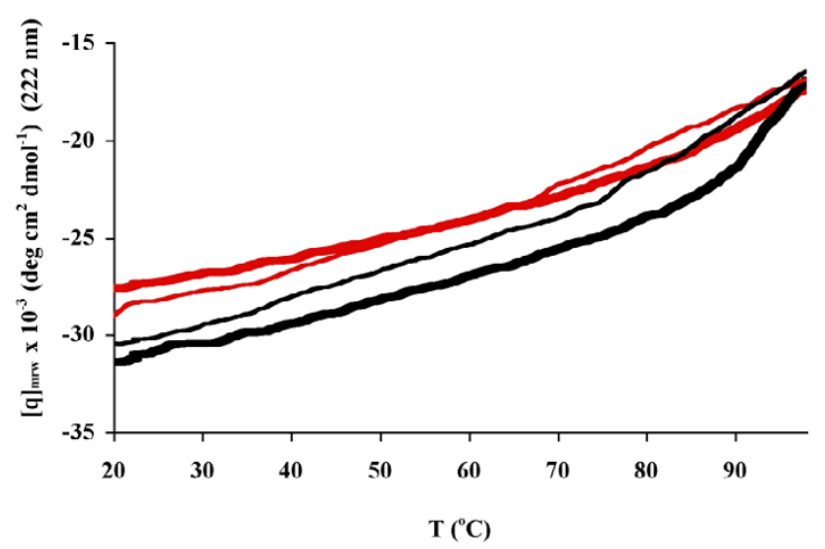

Figure 2

Circular dichroism spectroscopy. A. CD spectra of the CaM-peptide complex (red) and CaM (black). CaM was used at $0.050 \mathrm{mg} / \mathrm{ml}$ (in both samples) and the peptide at 0.030 $\mathrm{mg} / \mathrm{ml}$. B. Thermal stability curves of CaM (black) and the complex (red), monitored at $222 \mathrm{~nm}$. Mean residue ellipticity as a function of temperature was measured during heating from +20 to $+98^{\circ} \mathrm{C}$ (thick lines). Refolding of the samples during cooling from +98 to $+20^{\circ} \mathrm{C}$ is indicated by the thin lines.

suggests a large fraction of $\beta$-strand in the peptide in the absence of CaM, this reflects, rather, the inadequacy of the method for calculating the structure of a short peptide (or an unfolded protein), which is mostly unfolded, and probably contains a mixture of transient structures. For the structure modeling (see below), the peptide was modeled as a helix due to its homology to other (kinase) peptides that always bind CaM in a helical conformation (but are indeed disordered when not bound).

A thermal scan from +20 to $+98^{\circ} \mathrm{C}$ demonstrated that the complex as well as CaM is thermally very stable, showing the presence of folded structure even at temperatures exceeding $+95^{\circ} \mathrm{C}$ (Figure $2 \mathrm{~B}$ ). A major transition, increas-
Table I: Deconvolution of the CD spectra into secondary structure content, using $\mathbf{k} 2 \mathrm{~d}$. The results obtained by subtracting the CaM and peptide spectra from the complex spectrum are shown on the last two rows.

\begin{tabular}{llll}
\hline Sample & $\alpha$-Helix & $\beta$-Sheet & Random coil \\
\hline CaM & 0.88 & 0 & 0.12 \\
peptide & 0.05 & 0.47 & 0.48 \\
Complex & 0.72 & 0.03 & 0.25 \\
Complex-CaM & 0.03 & 0.50 & 0.47 \\
Complex-peptide & 0.72 & 0.03 & 0.26 \\
\hline
\end{tabular}

ing the denaturation speed, occurs at a temperature of around $+90^{\circ} \mathrm{C}$ for both samples. This transition is more pronounced in the absence of the peptide (CaM alone), which may indicate a stabilising effect by the peptide. Furthermore, cooling the samples back to $+20^{\circ} \mathrm{C}$ in a similar fashion induced refolding of CaM (Figure 2C), and the presence of the peptide did not cause significant differences in the refolding.

\section{Calorimetric binding assay}

Isothermal titration calorimetry was used to study the interaction between the MBP peptide and CaM (Figure 3). Experiments were done at four different temperatures $\left(+25,+30,+35\right.$, and $\left.+40^{\circ} \mathrm{C}\right)$, and the calculated thermodynamic parameters are presented in Table 2 . The $\mathrm{K}_{\mathrm{d}}$ values obtained were similar at temperatures below $+35^{\circ} \mathrm{C}$, and the heat-dependent conformational change of CaM most likely slight unfolding of the central linker helix [27], starting around $+35^{\circ} \mathrm{C}$, can be seen in the measured $\Delta \mathrm{H}$ values, that also become unreliable at $+40^{\circ} \mathrm{C}$ while the affinity is decreased. The binding reaction has favourable enthalpy and entropy, being mainly entropically driven. The favourable entropy is, at least partially, a result of releasing ordered water into solution from the surfaces of the binding components.

The binding isotherms were characteristic of a biphasic binding event, in which first, a high-affinity specific binding occurs, and in the later stages of titration, a low-affinity nonspecific binding, with a large number of binding sites and favourable enthalpy, can be detected. The latter is probably due to electrostatic interactions between the peptide and CaM, after the single specific binding site is saturated. The measured dilution heat was basically zero (Figure 3A), and it was assumed that the titrations will each time approach zero.

To characterize the binding of the peptide to the specific binding site of CaM, only the peaks 2-7 were chosen for curve fitting to model 1:1 binding (Figure 3B). When using all data (data points 2-20), the best curve fitting could be obtained by using an artificial model implementing four sequential binding sites (Figure 3C). In both 

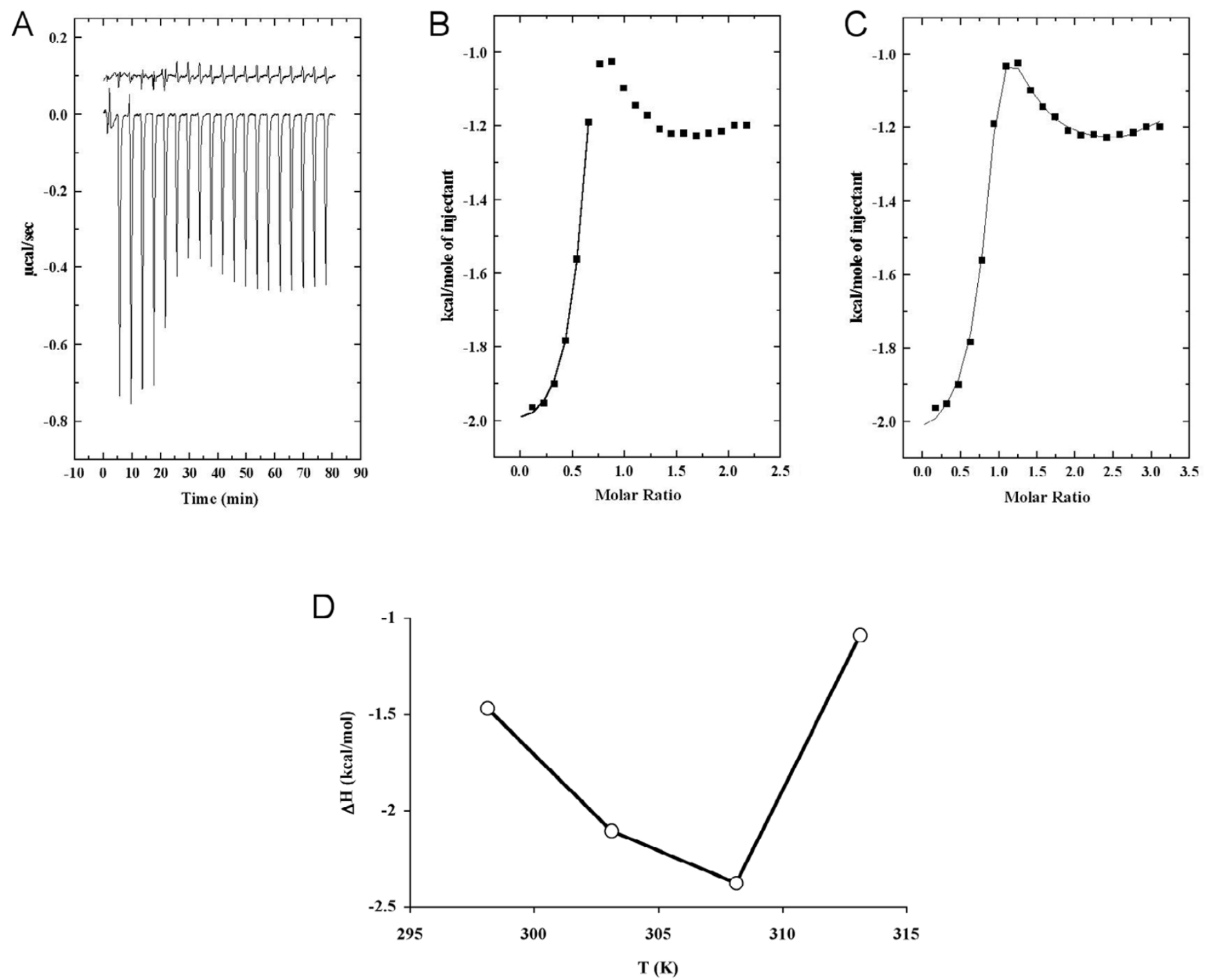

\section{Figure 3}

Isothermal titration calorimetry. A. Titration of the MBP peptide $(\mathrm{I} \mathrm{mM})$ into a solution of $\mathrm{CaM}(0 . \mathrm{I} \mathrm{mM})$ at $+30^{\circ} \mathrm{C}$. The results of a control reaction, where the MBP peptide was titrated into buffer at $+30^{\circ} \mathrm{C}$, are indicated above, moved up by 0.1 $\mu \mathrm{cal} / \mathrm{s}$ for clarity. B. Fitting for the specific binding site only. The solid line indicates the non-linear least squares fit for the integrated area under peaks $2-7$. The fitting model is one binding site. C. Fitting of all data to a multi-site model. The solid line indicates the non-linear least squares fit for the integrated area under peaks 2-20. The used model is for 4 sequential binding sites. Only the parameters for first binding event were used for analysis. $D$. The observed enthalpy as a function of temperature. The heat capacity $\left(\Delta C_{p}=-0.13 \mathrm{kcal} \mathrm{mol}^{-1} \mathrm{~K}^{-1}\right)$ is the slope calculated by using $\Delta H$ values at temperatures +25 and $+30^{\circ} \mathrm{C}$.

cases, the thermodynamic parameters for the first, highaffinity, binding event are highly similar (Table 2). This indicates that accurate values could be obtained for the high-affinity binding event even in the presence of nonspecific background.

The effect of temperature on the enthalpy of binding, which can be reliably measured even in the presence of secondary low-affinity binding sites, is presented in Figure
3D. The enthalpies from the calorimetric studies were plotted against temperature and the formed slope (between $25-30^{\circ} \mathrm{C}$ ) represents the heat capacity change $\Delta C_{p}$ upon complex formation. The heat capacity, estimated from the two data points at +25 and $+30^{\circ} \mathrm{C},-0.13$ $\mathrm{kcal} \mathrm{mol}^{-1} \mathrm{~K}^{-1}\left(-0.54 \mathrm{~kJ} \mathrm{~mol}^{-1} \mathrm{~K}^{-1}\right)$, is negative for the complex. It is clear that more assays should be performed to obtain an accurate value for $\Delta C_{p}$ of the complex. 
Table 2: Thermodynamic parameters from ITC of the MBP peptide binding to CaM. The shown values are from fitting for the specific binding site only. In parentheses, the values for the first binding event are given when fitting is done to a 4-site model.

\begin{tabular}{lllll}
\hline$T$ & $\mathrm{~K}_{\mathrm{d}}(\mu \mathrm{M})$ & $\Delta H(\mathrm{kcal} / \mathrm{mol})$ & $-T \Delta S(\mathrm{kcal} / \mathrm{mol})$ & $n$ \\
\hline $298.15 \mathrm{~K}\left(25^{\circ} \mathrm{C}\right)$ & $3.4(\mathrm{I} .0)$ & $-1.47 \pm 0.13(-1.44 \pm 0.04)$ & $-6.00(-6.73)$ & $0.83 \pm 0.23(\mathrm{I})$ \\
$303.15 \mathrm{~K}\left(30^{\circ} \mathrm{C}\right)$ & $2.3(\mathrm{I}) \mathrm{I})$ & $-2.11 \pm 0.06(-2.07 \pm 0.02)$ & $-5.7 \mathrm{I}(-6.18)$ & $0.67 \pm 0.02(\mathrm{I})$ \\
$308.15 \mathrm{~K}\left(35^{\circ} \mathrm{C}\right)$ & $1.9(1.0)$ & $-2.38 \pm 0.10(-2.34 \pm 0.03)$ & $-5.67(-6.13)$ & $0.63 \pm 0.02(\mathrm{I})$ \\
$313.15 \mathrm{~K}\left(40^{\circ} \mathrm{C}\right)$ & $25.9(\mathrm{I})$ & $-1.09 \pm 0.97(-0.73 \pm 0.05)$ & $-5.48(-7.56)$ & $0.70 \pm 0.17(\mathrm{I})$ \\
\hline
\end{tabular}

\section{Surface plasmon resonance}

The interaction of the peptide and CaM was further studied by real-time biomolecular interaction analysis with surface plasmon resonance (SPR). The kinetics of the binding reaction were studied by injecting different concentrations of the MBP peptide over an immobilised CaM surface (Figure $4 \mathrm{~A}$ ). The data confirm the binding of the MBP peptide by immobilised CaM, and a $K_{d}$ value of 58 $\mu \mathrm{M}$ can be estimated from the data. The difference in the $K_{d}$ values obtained by SPR and ITC may be explained by the fact that CaM was immobilised on a solid support for the SPR analysis. The data could only be properly fit by a conformational change model $\left(A+B<->A B<->A B^{*}\right)$, in which, upon initial complex $(\mathrm{AB})$ formation, the conformation of the complex alters $\left(\mathrm{AB}^{*}\right)$. Even so, it became clear that the signal for the second conformation $\left(\mathrm{AB}^{*}\right)$ is lower than for the first $(\mathrm{AB})$, which significantly complicates the analysis and makes the calculated $\mathrm{k}_{\text {on }}$ and $\mathrm{k}_{\text {off }} \mathrm{val}$ ues $\left(\mathrm{k}_{\mathrm{a} 1}=6700 \mathrm{M}^{-1} \mathrm{~s}^{-1}, \mathrm{k}_{\mathrm{d} 1}=0.14 \mathrm{~s}^{-1}, \mathrm{k}_{\mathrm{a} 2}=0.004 \mathrm{~s}^{-1}, \mathrm{k}_{\mathrm{d} 2}=\right.$ $\left.0.011 \mathrm{~s}^{-1}\right)$, especially for the second step of the reaction, unreliable. It is not possible to take such a situation into account in the BIAevaluation software, and in order to obtain a good fit, it was necessary to use additional parameters to describe the background level. A decrease in the SPR signal between two conformations has been observed previously for the binding of small molecules by a maltose-binding protein [28]. Ligand binding to a receptor that correspondingly decreases in hydrodynamic radius yielded a negative change in resonance units (RU). It was also proposed that the sign of the RU change is a function of the net change in hydrodynamic radius that occurs upon ligand binding [28]. Since by using the equilibrium RU values, the obtained Scatchard plot is curved (not shown), it is possible that similarly to the ITC experiment, the SPR signal is a combination of low- and highaffinity binding events. A further analysis of the data by non-linear regression by using a 2-site binding model (in GraphPad Prism) and the RU values at equilibrium gives evidence that a low-affinity binding event is seen at high concentrations of the peptide, and the corresponding $K_{d}$ values are approximately 10 and $1000 \mu \mathrm{M}$ for the two binding events.

The conformational change model for the interaction was also suggested by the linked reaction control experiment, in which the dissociation rates of one analyte concentration $(20 \mu \mathrm{M})$ after different injection times were compared (Figure 4B). An increased stability of the complex with longer injection times can be observed from the fact that the dissociation rates get slower with increased injec-
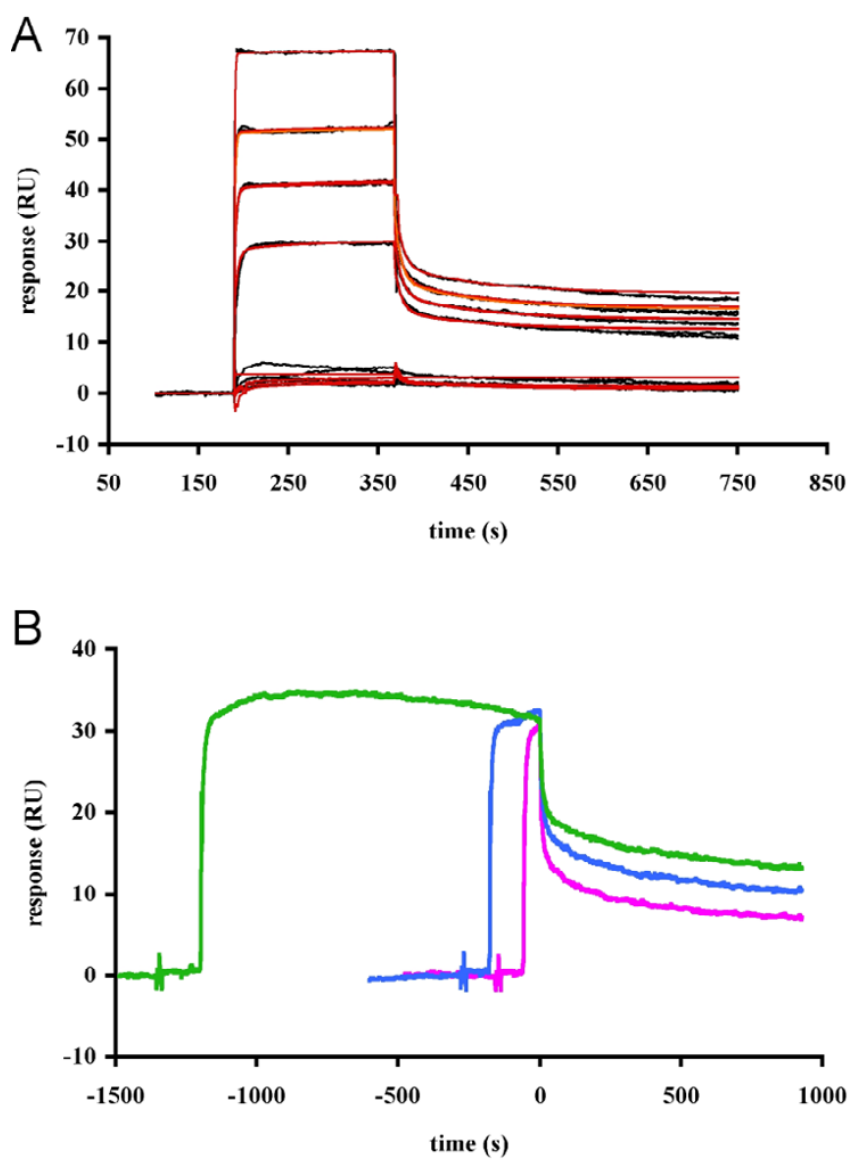

\section{Figure 4}

Surface plasmon resonance. A. SPR sensorgrams (black) of the binding of the MBP peptide (duplicate assays using 2.5, $5,20,50,100$, and $200 \mu M$ ) onto immobilized CaM. Data were fit to the two-state conformational change model, and the resulting fit is shown in red. $B$. Control experiment for linked reactions (heterogeneity test) by SPR. The sensorgrams have been aligned to the end point of the injection. The injection times are as follows: I min (magenta), 3 min (blue), 20 min (green). 
tion time. The experiment clearly showed that longer injections of the MBP peptide give a more stable CaMpeptide complex, which also suggests the occurrence of a conformational change. Furthermore, during longer injections, the signal decreases already during the injection, indicating that the signal for the $\mathrm{AB}^{*}$ state is indeed lower than that for the $\mathrm{AB}$ state.

\section{Mapping the MBP-binding site of CaM by nuclear magnetic resonance (NMR) spectroscopy}

NMR spectroscopy was used to identify CaM residues whose chemical shifts change upon forming the $\mathrm{Ca}^{2+}$ CaM-MBP peptide complex (Figure 5). To the most part, these residues are concentrated around the known peptide binding pocket of the CaM C-terminal lobe. Identified residues in this region include, for example, Leu105, Arg106, Ala128, Phe141, Gln143, Ala147, and Lys148.

The result that chemical shift perturbations were also observed for residues in the central helix indicates either bending of the helix upon peptide binding or a direct interaction between the peptide and the central helix. The chemical shift perturbations of some residues, mainly Phe12 and Lys13, of the N-terminal lobe suggest that the peptide is not only bound to the C-terminal lobe, but rather, interacts also weakly with the N-terminal lobe. Taken together, the NMR data show that the MBP peptide interacts most significantly with the hydrophobic pocket in the CaM C-terminal lobe, but also with parts of the central helix and the N-terminal lobe. These data were further used as restraints when building and refining a solution structure of the complex using small-angle X-ray scattering (SAXS) (see below).

\section{Solution structure from SAXS Overall parameters}

The experimental scattering patterns from free CaM and the complex are presented in Figure 6A, and the overall structural parameters computed from the SAXS data are given in Table 3. The molecular mass and the volume of the complex exceed those of free CaM by about $14 \%$. This increase is fully compatible with that expected $(12 \%)$ from the sequences of CaM and the peptide, which proves the formation of a 1:1 complex. On the other hand, the maximum diameter of the complex is practically unchanged, and its radius of gyration is even smaller than that of free CaM. This suggests that CaM keeps the extended conformation in the complex and that the peptide is bound to the central part of CaM, rather than to its periphery. The scattering curve from the atomic model of CaM was computed by the program CRYSOL [29]. It agrees reasonably with the experimental data showing only some minor deviations (Figure 6A, Table 3), which may be attributed to incompleteness of the crystallographic model.

\section{Distance distribution functions}

The distance distributions $p(r)$ of the two samples computed from the experimental data by the program GNOM [30] are given in Figure 6B. These functions are similar up to intraparticle distances of $1.2 \mathrm{~nm}$ but display different profiles at larger distances. The $p(r)$ of free CaM has a skewed form characteristic for elongated particles, and the maximum in the $p(r)$ function at about $4 \mathrm{~nm}$, corresponding to the distance between the two lobes of CaM, whereas the more symmetric $p(r)$ of the complex clearly points to a more globular shape. Taken together, the comparison of distance distribution functions also confirms the complex formation, with the interface at the central part of CaM. A decrease in CaM length upon peptide binding, as observed in a number of structures of high-affinity CaMpeptide complexes [31-33] is not observed. Ab initio shapes of free and loaded CaM generated by DAMMIN (not shown) also confirm that there is no significant change in the maximum dimension of CaM upon peptide binding.

\section{Shape determination}

The $a b$ initio model of the complex highlighting the location of the peptide was generated by the multiphase bead modeling program MONSA [34]. Several independent runs yielded reproducible results, in which experimental scattering profiles were neatly fitted (Figure 6A, Table 3). The models created by MONSA were very similar to those generated by DAMMIN independently for free and loaded CaM. This finding supports the assumption that no significant change of overall shape occurs upon binding and the use of the two curves for simultaneous fitting by MONSA is valid. A typical model selected by DAMAVER [35] presented in Figure 7 yielded an average normalised spatial discrepancy (NSD) value below 1.0 (see Materials and Methods). It demonstrates that the peptide is positioned between the two lobes of CaM, being closer to one of them. The overall appearance is, thus, in agreement with the conclusions made from primary data processing.

\section{Molecular modelling}

The crystallographic model of CaM is compatible with the experimental SAXS data from the free protein, and no significant compaction of CaM was observed in the complex. As small conformational changes upon peptide binding could still not be excluded, we split CaM into three fragments (central helix, $\mathrm{N}$ - and C-termini of CaM) for the molecular modelling of the complex. The peptide was modelled as a helix for simplicity and due to homology, but the low resolution of the SAXS data does not allow for the determination of the exact conformation of the peptide. The program SASREF [36] was employed to construct a low-resolution 3D model of CaM loaded with the peptide by using distance restraints from NMR data and requirement of chain compatibility for the three CaM seg- 

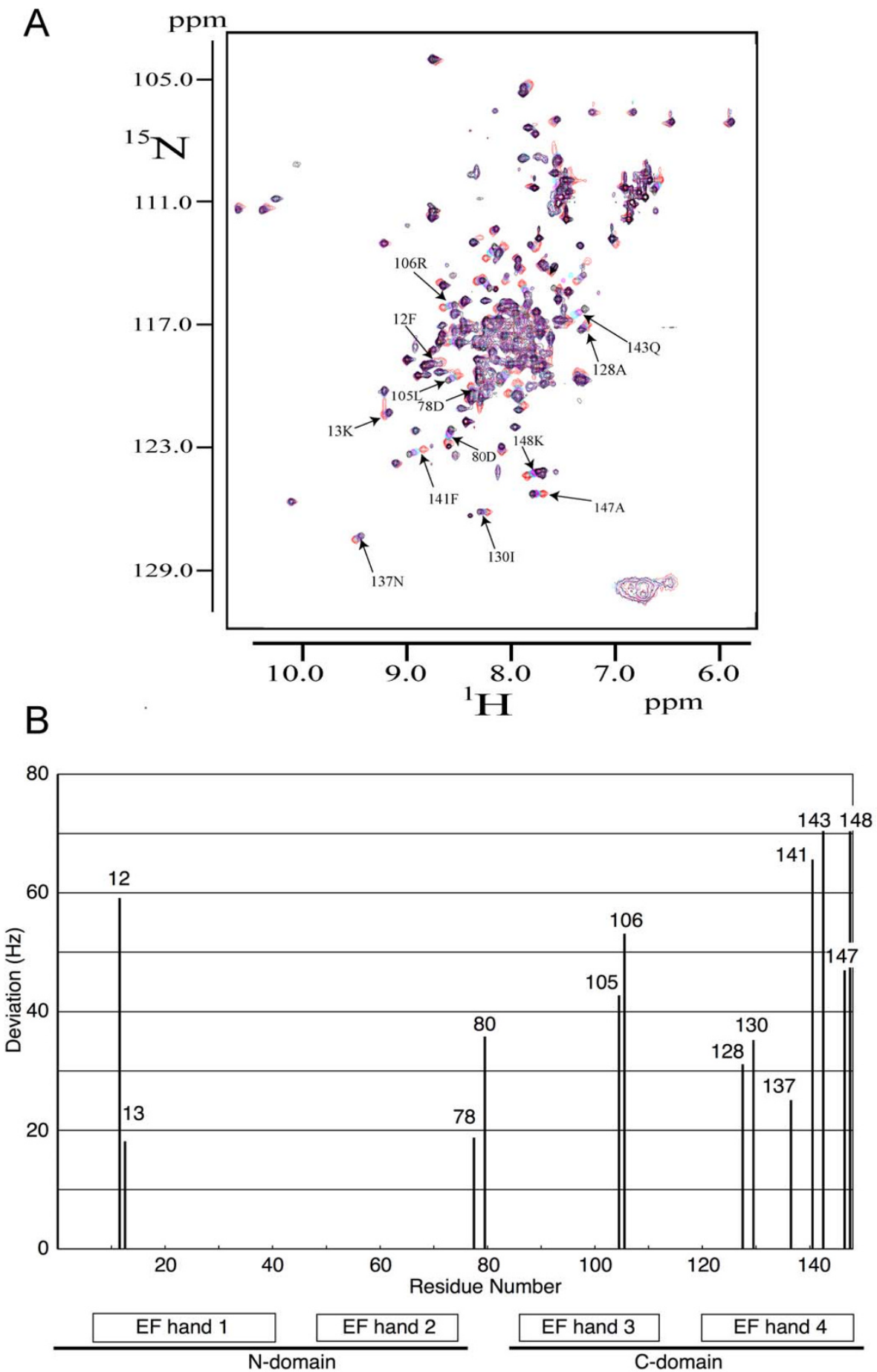

\section{Figure 5}

${ }^{1} \mathrm{H}-{ }^{15} \mathrm{~N}$ HSQC spectra for the titration of $\mathrm{CaM}$ with the MBP peptide. A. Overlay of ${ }^{1} \mathrm{H}-{ }^{15} \mathrm{~N} \mathrm{HSQC} \mathrm{spectra} \mathrm{of} \mathrm{Ca}^{2+} /$ $\mathrm{CaM}$ alone (black) and the $\mathrm{Ca}^{2+} / \mathrm{CaM}-\mathrm{MBP}$ peptide complex (pink; I:0.333, blue; I:0.666, red; I:I). The samples contained 0.5 $\mathrm{mM} \mathrm{CaM}, 120 \mathrm{mM} \mathrm{NaCl}, 2.5 \mathrm{mM} \mathrm{CaCl}_{2}$, and $50 \mathrm{mM}$ deuterated Tris- $\mathrm{HCl}(\mathrm{pH} 7.5)$ in $90 \% \mathrm{H}_{2} \mathrm{O}$ and $10 \% \mathrm{D}_{2} \mathrm{O}$. Changes in cross-peak positions were quantified by $\left[\left(\Delta^{15} \mathrm{~N}_{\mathrm{Hz}}\right)^{2}+\left(\Delta^{1} \mathrm{H}_{\mathrm{Hz}}\right)^{2}\right]^{1 / 2}$, and some cross-peaks showing larger shifts are indicated on the figure. B. Chemical shift perturbations quantified by $\left[\left(\Delta^{15} \mathrm{~N}_{\mathrm{Hz}}\right)^{2}+\left(\Delta^{1} \mathrm{H}_{\mathrm{Hz}}\right)^{2}\right]^{1 / 2}$. Residues with large perturbations $\left(\left[\left(\Delta^{15} \mathrm{~N}_{\mathrm{Hz}}\right)^{2}\right.\right.$ $\left.\left.+\left(\Delta^{\prime} \mathrm{H}_{\mathrm{Hz}}\right)^{2}\right]^{1 / 2}>10.0\right)$ are shown. Numbers of each bar show their residual numbers. Positions of four EF hands are also indicated under the graph 
A $\quad \mathrm{I}(\mathrm{s})$, relative

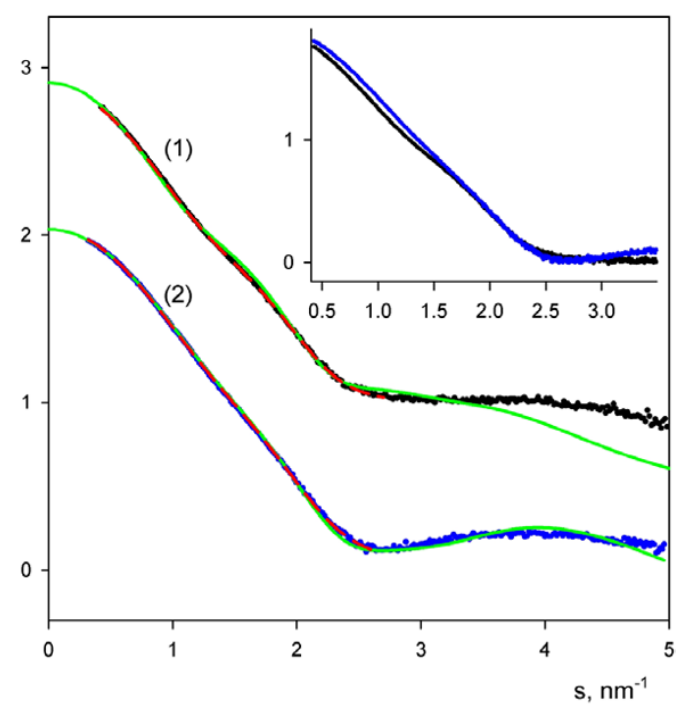

$\mathrm{B}$

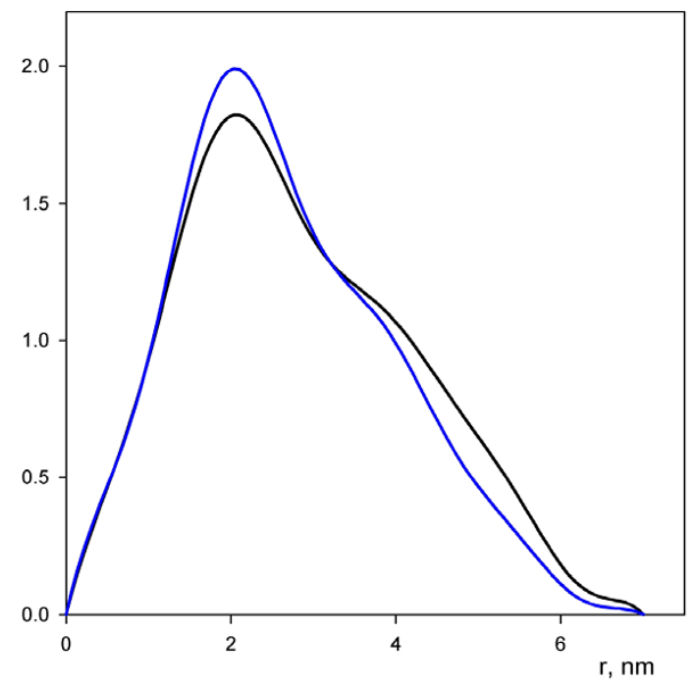

Figure 6

Scattering profiles and distance distribution functions of free and loaded CaM. A. Scattering data of CaM ( $I$, black dots) and the complex (2, blue dots). Dots denote the experimental scattering data, the fits obtained by MONSA are displayed as red dashed lines, and the fits of the crystal structure of CaM and the rigid body model of the complex are shown as green solid lines. The plot displays the logarithm of the scattering intensity as a function of momentum transfer $s=4 \pi \sin (\theta) / \lambda$, where $2 \theta$ is the scattering angle and $\lambda=0.15 \mathrm{~nm}$ is the X-ray wavelength. The curves are arbitrarily displaced along the logarithmic axis for better visualization. The insert presents a direct comparison of the experimental curves without displacement. B. $p(r)$ functions computed from the experimental $X$-ray scattering patterns using the program GNOM. The functions are presented in arbitrary units; the colouring scheme is the same that as used for the experimental data in $(A)$. ments (see details in Methods). This approach assumes that the CaM residues with the largest chemical shift perturbations in the NMR experiment interact closely with the peptide, which may not be strictly true for all of them. A typical rigid body model of the complex generated in multiple SASREF runs (Figure 7) yields a good fit to the experimental data of the complex (Figure 6A, Table 3). The overall shape of $\mathrm{CaM}$ in the rigid body modelling remains similar to that of free CaM. Similarly to the $a b i n i-$ tio modelling results, the results suggest that the peptide is located between the two lobes, and more specifically, the tighter contact between the peptide and the C-terminal lobe observed by NMR is compatible with the SAXS results. It should be mentioned that at the given resolution, the models with antiparallel orientations of the peptide-helix are not distinguishable from each other, and solutions with both peptide directions were obtained, yielding the same fit to the SAXS data.

\section{Size exclusion chromatography}

To further validate the determined solution structure of the complex, we carried out gel filtration chromatography and analysed the fractions by SDS-PAGE and silver staining, allowing the visualisation of both CaM and the peptide (Figure 8). Due to its highly extended conformation, free CaM routinely runs at an apparent molecular weight of approximately $30 \mathrm{kDa}$ in gel filtration. A superposition of the chromatograms (Figure 8A) in the presence and absence of the peptide indicates that the hydrodynamic radius of CaM is indeed decreased in the presence of the peptide. An analysis of the collected fractions clearly shows that the large, slightly shifted, peak contains both $\mathrm{CaM}$ and the peptide (Figure 8B).

\section{Discussion}

Native human brain MBP and a peptide from the MBP Cterminus bind CaM

An analysis of native human brain MBP indicated that it interacts directly with CaM in a calcium-dependent manner. A calcium-dependent interaction between human MBP and CaM has previously been reported for two MBP charge isoforms isolated from a patient suffering from multiple sclerosis [20], as have calcium-dependent interactions between bovine and murine MBP and CaM [1719].

The human brain MBP sample contained isoforms of 17.2 and 18.5 (predominant) $\mathrm{kDa}$ after calmodulin affinity chromatography. Thus, the regions encoded by neither exon II (missing in both isoforms) nor exon Vb (missing in the $17.2-\mathrm{kDa}$ isoform) are required for the interaction. Only these two major isoforms are expressed in adult brain $[37,38]$. The two other major isoforms, 20.2 and $21.5 \mathrm{kDa}$, are expressed during myelination, as well as during remyelination in MS lesions [39]. 
Table 3: Structural parameters defined from the experimental SAXS data. $I_{0}, R_{g}, V_{p}$ and $D_{\max }$ are, respectively, the forward scattering, radius of gyration, excluded volume and maximum size calculated from the scattering data. $\chi_{s}$ and $\chi_{\mathrm{rb}}$ are discrepancies between the experimental data and computed scattering curves from typical ab initio and rigid body models (crystallographic model in case of free calmodulin).

\begin{tabular}{lllllll}
\hline Sample & $\mathrm{I}_{0}$, relative & $\mathrm{R}_{\mathrm{g}}, \mathrm{nm}$ & $\mathrm{V}_{\mathrm{p}}, \mathrm{nm}^{3}$ & $\mathrm{D}_{\max }, \mathrm{nm}$ & $\chi_{\mathrm{s}}$ & $\chi_{\mathrm{rb}}$ \\
\hline Calmodulin & $95.0 \pm 5$ & $2.22 \pm 0.05$ & $34 \pm 2$ & $7.0 \pm 0.5$ & 0.8 & 2.4 \\
Calmodulin+peptide & $108.0 \pm 3$ & $2.08 \pm 0.05$ & $39 \pm 2$ & $7.0 \pm 0.5$ & 0.8 & 1.1 \\
Ratio & 1.14 & 0.94 & 1.15 & 1.0 & - & - \\
\hline
\end{tabular}

A CaM-binding site of MBP has been localised to the Cterminal region, but so far, a detailed mapping has been lacking $[20,21]$. By the use of various bioinformatics methods and sequence comparisons to known CaM ligands, we were able to design a 19-residue peptide based on the sequence of human MBP that binds to CaM with micromolar affinity. The measured affinity for the peptide towards CaM was similar or slightly weaker than observed previously for full-length MBP and a C-terminal proteolytic fragment thereof $[18,21]$. Although the observed affinity, in the low micromolar range, is lower than for some other CaM targets, it suggests a physiological relevance for the interaction, taking into account the following points: Firstly, the concentration of MBP in myelin is
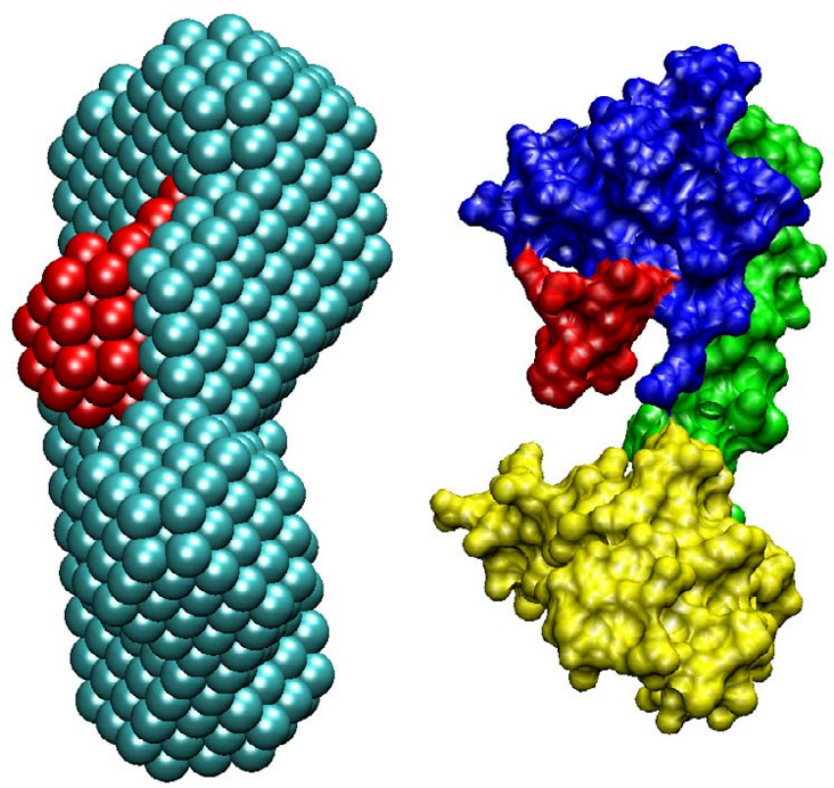

Figure 7

$A b$ initio and rigid body models of the complex. Left panel: two-component shape of the complex generated by MONSA; Right panel: the rigid body model built by SASREF. The peptide parts are given in red. The central helix and the $\mathrm{N}$ - and $\mathrm{C}$-terminal lobes of $\mathrm{CaM}$ in the rigid body model are shown in green, yellow, and blue, respectively. The handedness of the $a b$ initio MONSA model was chosen that provides the best agreement (lowest NSD) with the rigid body model. very high, and the concentration of CaM in cells is also in the order of $1-10 \mu \mathrm{M}[40]$, even higher in the nervous system [41]. Thus, the measured affinity is in the range that can regulate the interactions between these two highly abundant proteins. Secondly, it is likely that the surrounding regions of $\mathrm{MBP}$, being highly positively charged, can interact with and possibly even wrap around $\mathrm{CaM}$, once the specific recognition of the binding site has occurred; this would be expected to increase the affinity for complex formation. Furthermore, the presence of more than one binding site for CaM in MBP raises the possibility of socalled allovalency [42], effectively increasing the affinity.

It should be noted that in other vertebrate species, insertions of 1-2 residues are seen near the middle of the peptide that was used (see Methods). This implies either that there may be subtle species-specific differences in the interaction between CaM and this MBP segment, or that the entire length of the peptide is not necessary for the interaction. For example, it is possible that only one half of the used MBP peptide is in close contact with the C-terminal lobe of $\mathrm{CaM}$; high-resolution structural data would be required to fully address this issue.

The region, from which the peptide was selected, is also a target for MBP posttranslational modifications. Ser151 can be phosphorylated [43] and Gln147 deamidated [44]. Both of these modifications will add a negative charge to the corresponding position, thus likely decreasing the affinity for CaM. No citrullination sites are present in the peptide, however, due to the lack of arginine residues. On both sides of the used peptide, the MBP sequence does harbour characterised citrullination sites [45], which could, in principle, also regulate binding to CaM.

\section{Energetics of the CaM-MBP peptide interaction}

The heat capacities of several CaM-associated reactions have been reported and discussed earlier [46]. Temperatures below $+30^{\circ} \mathrm{C}$ have been systematically used for ITC binding studies with CaM and CaM-binding peptides. This is important in order to prevent temperature-induced conformational changes in CaM $[27,47]$; this effect is also seen in our data, making measurements at high temperatures unreliable. CaM-binding peptides have been 
A

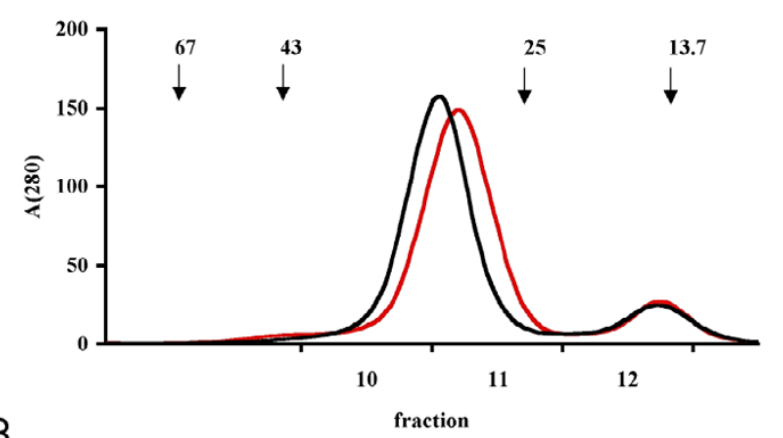

B

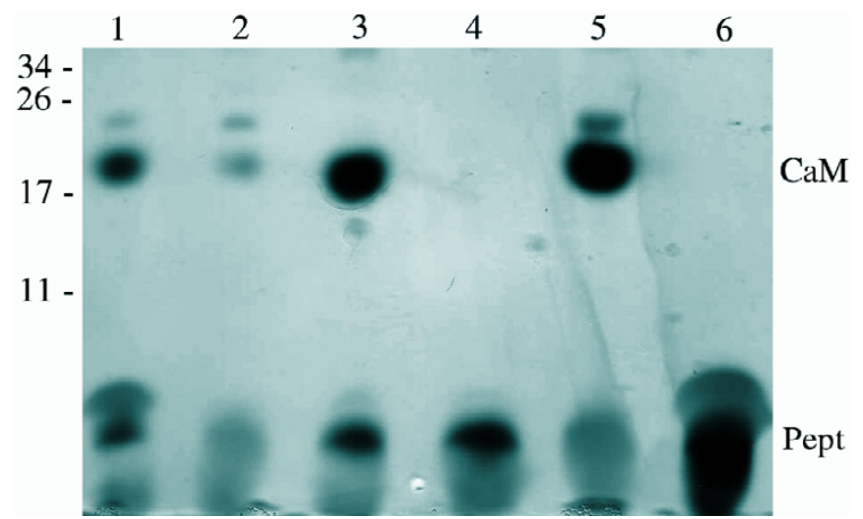

Figure 8

Gel filtration of $\mathrm{CaM}$ in the presence and absence of the MBP peptide. A. The elution profiles of CaM (black) and the complex of CaM and peptide (red) from a Superdex 75 column. The arrows above indicate the elution volumes and molecular weights (in $\mathrm{kDa}$ ) of the standard proteins used to calibrate the column. The positions of the collected fractions from the complex sample are indicated below the graph. The absorbances have been multiplied by 1000 for clarity. B. Electrophoretic analysis of the fractions obtained from the complex sample on a 16.5-\% Tris-tricine peptide gel. The samples are as follows: I, the CaM-peptide mixture injected into the column; 2 , fraction I0; 3 , fraction II; 4, fraction I2; 5, CaM; 6, peptide. The positions of molecular weight markers (in $\mathrm{kDa}$ ) are indicated on the left, and the positions of $\mathrm{CaM}$ and the peptide are indicated on right. Note how the peak fraction (lane 3 ) contains both CaM and the peptide. A weak low-molecular-weight shadow is also seen in the CaM sample (lane 5), but the peptide stains intensely dark with silver and can unequivocally be detected based on its colour. The faint band above CaM is most likely another conformation of CaM.

roughly divided into two groups depending on the heat capacity upon their complex formation with CaM [46]. CaM-dependent protein kinase I, constitutive cerebellar nitric-oxide synthase, and melittin peptides have $\Delta C_{p}$ values around $-0.8 \mathrm{kcal} \mathrm{mol}^{-1} \mathrm{~K}^{-1}$, which reflects their preference for the formation of a globular CaM-peptide complex. The second group, having a $\Delta C_{p}$ of $-0.4 \mathrm{kcal} \mathrm{mol}^{-}$ ${ }^{1} \mathrm{~K}^{-1}$, is composed of phosphodiesterase, the C-terminal fragment of melittin, and chicken gizzard caldesmon peptides, which interact mainly with one lobe of CaM [46]. In our current study, the estimated $\Delta C_{p}$ of the formed complex is $-0.13 \mathrm{kcal} \mathrm{mol}^{-1} \mathrm{~K}^{-1}$, which is different from the above cases and can indicate different type of binding compared to the two previously discussed groups of peptides. In fact, it directly suggests a smaller buried surface area than in the other CaM-peptide complexes - an idea which is indeed confirmed by our NMR and SAXS studies.

\section{The structure of the CaM-MBP peptide complex in solution}

SPR indicated that the complex formed between immobilised CaM and the MBP peptide underwent a conformational change upon binding. A conformational change was also detected by SPR when the complex between CaM and the ERR3 receptor was studied [48]. A negative change in $\mathrm{RU}$, as observed here for the CaM-MBP complex, during the injection may reflect a decrease in the hydrodynamic radius of the forming complex [28]. This is also in line with our results from gel filtration chromatography, in which the apparent size of CaM is decreased in the presence of the peptide, indicating a smaller hydrodynamic radius for the complex than for unliganded CaM. On the other hand, as expected, CD spectroscopy clearly indicated that no large-scale changes in secondary structure content occur upon binding.

The solution structure of the CaM-MBP peptide complex obtained with SAXS is compatible with all of the other experiments we carried out on the complex. In essence, the SAXS results indicate that the maximum diameter of CaM does not change when bound to the MBP peptide, and the radius of gyration for the complex is slightly smaller than that of free CaM. This result is fully compatible with the result from gel filtration chromatography. The peptide can be seen bound to a groove in the central region of CaM (slightly closer to the C-terminal lobe), which remains in the extended conformation. In other words, CaM does not collapse around the MBP peptide, as seen in several other instances of CaM-peptide recognition [31-33].

It is possible that the CaM-MBP peptide complex has several conformations in solution; however, the fact that both the $a b$ initio and rigid body models from SAXS fit the measured data well (Figure 6) indicates that it is likely that only one major conformation is present, at the resolution that has been used in the current study. This is also supported by gel filtration chromatography (Figure 8 ), where significantly different conformations of the complex could yield different peaks or peaks with non-symmetric 
shapes, since the starting point is $\mathrm{CaM}$, an elongated dumbbell-shaped molecule.

Our NMR data indicate that although the main binding site for the MBP peptide resides in the C-terminal lobe of $\mathrm{CaM}$, also the central helix and the N-terminal lobe interact with the peptide. Comparing the structures of our model and free CaM, the NMR data suggest that a rotation of the C-terminal lobe takes place upon binding, such that its hydrophobic pocket interacts closely with the peptide (Figure 9, Additional file 2). Furthermore, it should be noted that molecular modelling was used in an earlier study to predict the modes and energetics of binding of different short MBP peptides to CaM, including one overlapping with the peptide used in this study [22]. As a starting point in these simulations, the fully collapsed CaM structure from a kinase peptide complex was used. Our results indicate that this may have been an oversimplification, and that the conformation of CaM may be significantly different in the CaM-MBP complex.

For CaM-dependent protein kinases, it has been suggested that studies on CaM-binding peptides accurately reflect the interactions between CaM and the kinase [49]. It is possible that for MBP, regions outside the peptide studied here also participate in complex formation, possibly alter- ing the affinity and/or conformation of the complex, as has been observed for the deiminated form of MBP [20]. Interestingly, it has also been suggested that CaM might be able to bind two molecules of MBP simultaneously in a cooperative fashion, where both lobes of CaM would mainly interact with one MBP molecule [19]. Thus, the structure of the complex determined here may also represent an intermediate in the binding of full-length MBP by CaM.

\section{Conclusion}

Structural knowledge about myelin proteins in general is underrepresented in current databases [50,51], despite the presence of a well-characterised but relatively small set of specific proteins in the myelin sheath. We have carried out a detailed analysis of the interaction between CaM and a 19-mer peptide from the C-terminal region of human MBP, a major protein in the myelin sheath. MBP has been characterised as being intrinsically unstructured by nature [3]; however, it presents a multitude of post-translational modifications and binding partners, which, in turn, affect its functions in $e$.g. signaling and regulating the cytoskeleton [2]. We have shown that the complex formed between CaM and the MBP peptide does not collapse, although a conformational change takes place on a smaller scale, the main binding site for the MBP peptide residing in the
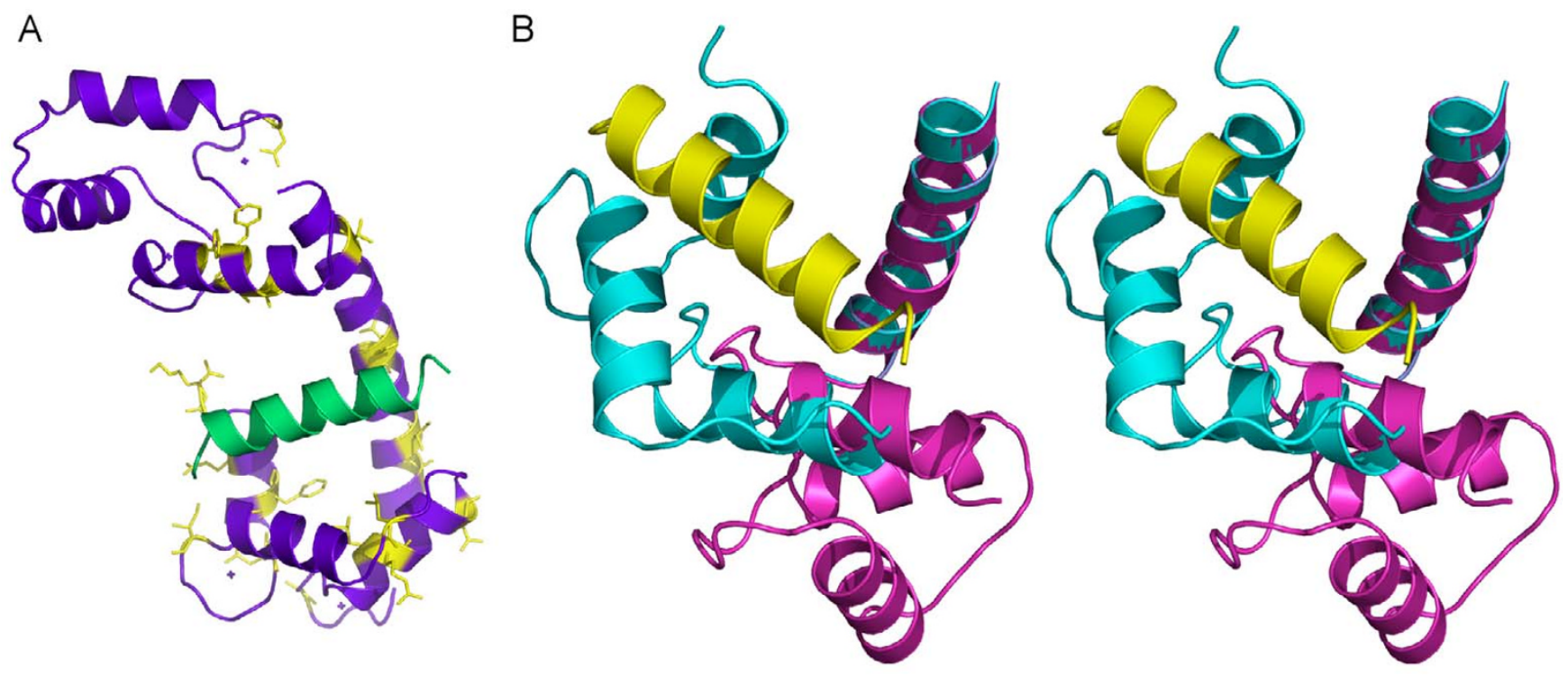

\section{Figure 9}

Mapping of the binding site of the human MBP peptide in CaM to the C-terminal lobe. It should be noted that the structures shown are extrapolations from the low-resolution SAXS model obtained by rigid-body fitting, as described in Methods. A. CaM (magenta) and the peptide (green) are shown as ribbons, and the interacting residues, based on the NMR experiment, are shown in stick mode with yellow colour. Note how the binding site is localised mainly to the hydrophobic pocket of the C-terminal (lower) lobe. B. Stereo view of the conformation of the CaM C-terminal lobe in free CaM (pink) and in the SAXS model of the complex (light blue). The peptide is shown in yellow, and superposition has been done using the residues of the central helix (pointing towards top right). The $\mathrm{N}$-terminal lobe is omitted from the figure for clarity. An animation of the predicted movement is shown in Additional file 2. 
hydrophobic pocket of the C-terminal lobe of CaM. With relatively weak binding, such as that observed between $\mathrm{MBP}$ and CaM, a massive conformational change may indeed not be required, and the binding affinity may be low in order to maintain the possibility of regulation, because the concentrations of both interaction partners in the cell are high. Thus, MBP is another CaM target that cannot be thought of as being analogous to CaM kinases with respect to the mode of CaM binding [52]. Our results provide an important structural insight into the factors that may regulate myelin formation and maintenance and further highlight the plasticity of CaM in target recognition.

\section{Methods}

\section{Sequence analysis}

A number of sequence analysis tools were applied in order to be able to select a suitable CaM-binding peptide from the C-terminal region of human MBP that has been suggested to carry a CaM-binding site $[20,21]$. Disorder predictions were carried out using DISembl $[53,54]$, GlobPlot [55,56], and DRIP-PRED [57]. Secondary structure predictions were done using the consensus method at the NPSA $[58,59]$. Putative functionally flexible regions were analysed with Wiggle [60]. The CaM target database $[25,61]$ was searched for putative CaM-binding segments within MBP, and in the end, the chosen region was manually aligned with CaM-binding regions from CaMdependent protein kinases. It should be noted that this method is unlikely to detect previously uncharacterised CaM-binding sites.

\section{Materials}

The MBP peptide chosen for the present study, HKGFKGVDAQGTLSKIFKL, corresponding to residues 138-156 of the human MBP $18.5 \mathrm{kDa}$ isoform, of $95 \%$ purity, was obtained from Genemed Synthesis. It should be noted that some other vertebrates have 1- or 2-residue insertions in this region, at position 145 . The peptide was dissolved in $50 \mathrm{mM}$ HEPES pH 7.5, $20 \mathrm{mM} \mathrm{CaCl}_{2}$ and stored at $-20^{\circ} \mathrm{C}$. The preparation of the CaM expression construct pETCM, containing vertebrate CaM cDNA, has been described earlier [62]. Native MBP protein isolated using the chloroform extraction method [63] from postmortem human brain was obtained from FermLab (Turku, Finland).

\section{Protein purification}

CaM was purified using calcium-dependent phenyl sepharose affinity chromatography $[62,64]$. pETCM was transformed into E. coli Rosetta (DE3), and one colony was transferred into $10 \mathrm{ml}$ of LB containing $100 \mu \mathrm{g} / \mathrm{ml}$ of ampicillin and grown for $7 \mathrm{~h}$ at $+37^{\circ} \mathrm{C}$. For expression, $1 \mathrm{l}$ of LB medium containing ampicillin $(100 \mu \mathrm{g} / \mathrm{ml})$ was inoculated with the $10 \mathrm{ml}$ culture. Induction was performed after $5 \mathrm{~h}$ with $0.4 \mathrm{mM}$ IPTG. The culture was further grown for $12 \mathrm{~h}$, and the cells were harvested by centrifugation. For stable isotope labeling, modified M9 medium [65] was used instead of the LB medium. The cells were suspended in $50 \mathrm{ml}$ of cold lysis buffer (10 mM HEPES pH 7.5, $1 \mathrm{mM}$ EDTA, $1 \mathrm{mM} \mathrm{NaN}_{3}, 10 \mathrm{mM}$ DTT, $10 \mu \mathrm{g} / \mathrm{ml}$ DNAse I), and lysozyme and RNAse A were added to 100 $\mu \mathrm{g} / \mathrm{ml}$ and $2 \mu \mathrm{g} / \mathrm{ml}$, respectively. Cell suspensions were stored at $-80^{\circ} \mathrm{C}$ until needed. Cells were disrupted by sonication. After centrifugation $(27000 \mathrm{~g}, 20 \mathrm{~min})$, the supernatant was heated in $\mathrm{a}+80^{\circ} \mathrm{C}$ water bath for $10 \mathrm{~min}$ and centrifuged $(27000 \mathrm{~g}, 20 \mathrm{~min}) .5 \mathrm{mM} \mathrm{CaCl}_{2}$ were added to the supernatant, and the sample was centrifuged once more.

The soluble proteins were applied to a phenyl sepharose column (Pharmacia Biotech Inc), equilibrated with 10 $\mathrm{mM}$ HEPES $\mathrm{pH} 7.5,4 \mathrm{mM} \mathrm{CaCl}_{2}$. The column was consecutively washed with excess equilibration buffer, equilibration buffer supplemented with $500 \mathrm{mM} \mathrm{NaCl}$, and equilibration buffer again. Elution of CaM was then carried out with $10 \mathrm{mM}$ HEPES pH 7.5, $5 \mathrm{mM}$ EGTA. The fractions were analyzed by SDS-PAGE, and the fractions containing CaM were pooled and concentrated by centrifugal ultrafiltration.

\section{Affinity chromatography of human brain MBP on CaM- sepharose}

Calcium-dependent affinity chromatography of human MBP on CaM-sepharose (GE Healthcare) was carried out as follows: $200 \mu \mathrm{g}$ of lyophilized human brain MBP were dissolved in $50 \mathrm{mM}$ HEPES pH 7.5, $150 \mathrm{mM} \mathrm{NaCl}, 2 \mathrm{mM}$ $\mathrm{CaCl}_{2}$. The same buffer that was used to equilibrate $100 \mu \mathrm{l}$ of the CaM-sepharose matrix. The sample was mixed with the matrix and washed with $5 \mathrm{ml}$ of the above buffer. Elution was done with $1.4 \mathrm{ml}$ of $50 \mathrm{mM}$ HEPES pH 7.5, 150 $\mathrm{mM} \mathrm{NaCl}, 2 \mathrm{mM}$ EGTA. The fractions were applied on a $18 \%$ SDS-PAGE gel. To detect which isoforms were bound to CaM-sepharose, fractions 2 (wash) and 7 (EGTA elution) were purified with Vivapure ${ }^{\circledast} \mathrm{C} 18$ Micro spin columns prior to analysis by mass spectrometry. MALDI-ToF mass spectrometry was performed with a Voyager-DE STR Biospectrometry Workstation (Applied Biosystems). $1 \mu \mathrm{l}$ of the protein sample was spotted on sinapinic acid matrix.

\section{Circular dichroism spectroscopy}

Far-UV CD spectra in the $196-250 \mathrm{~nm}$ region were recorded at $+20^{\circ} \mathrm{C}$ with a JASCO J-715 CD-spectropolarimeter (Jasco Corp., Tokyo, Japan), using a 1-mm path length quartz cell. The spectra were corrected by subtracting the spectrum of a buffer sample (10 mM HEPES $\mathrm{pH}$ $7.5,150 \mathrm{mM} \mathrm{NaCl}, 4 \mathrm{mM} \mathrm{CaCl} 2$ ). Noise reduction was applied to smooth the data with the Jasco software. The spectra are presented as mean residue ellipticity $(\theta)$, calcu- 
lated by using the molar concentration of peptide or protein and multiplying by the appropriate number of peptide bonds. CaM concentration in the sample was $0.050 \mathrm{mg} / \mathrm{ml}$ and the peptide concentration was 0.030 $\mathrm{mg} / \mathrm{ml}$. Secondary structure contents of the samples were estimated with the program k2d [26].

Thermal denaturation of CaM in the presence and absence of the MBP peptide was followed by monitoring the ellipticity at a fixed wavelength of $222 \mathrm{~nm}$ while the sample was heated at a rate of $30^{\circ} \mathrm{C} / \mathrm{h}$ from +20 to $+98^{\circ} \mathrm{C}$. Free CaM concentration in the sample was $0.15 \mathrm{mg} / \mathrm{ml}$ and in the CaM/peptide mixture, the concentrations of CaM and the peptide were 0.20 and $0.30 \mathrm{mg} / \mathrm{ml}$, respectively. A cooling experiment to monitor putative refolding of the protein was also similarly done for the same samples from +98 to $+20^{\circ} \mathrm{C}$ at a rate of $30^{\circ} \mathrm{C} / \mathrm{h}$

\section{Isothermal titration calorimetry}

The binding of the MBP peptide to CaM was studied by ITC, using a VP-ITC microcalorimeter (MicroCal, Norhampton, MA). The samples for the experiment were extensively dialysed against $50 \mathrm{mM}$ HEPES pH 7.5, 20 $\mathrm{mM} \mathrm{CaCl}_{2}$ and degassed in an ultrasonic water bath. The MBP peptide solution $(1.0 \mathrm{mM})$ was injected into the sample cell, containing $0.10 \mathrm{mM}$ CaM in the above buffer. The first injection of $2 \mu \mathrm{l}$ was followed by $1915-\mu \mathrm{l}$ injections of the peptide. The experiment was carried out at $+25,+30,+35$, and $+40^{\circ} \mathrm{C}$. The dilution heat was measured by titrating the buffer with the $1 \mathrm{mM}$ peptide solution. The heat of dilution was practically zero. The raw data were fitted by non-linear least squares minimisation with models for both a single site and four binding sites (see Results), using the Origin version 5.0 software (MicroCal).

\section{Surface plasmon resonance}

SPR assays were performed with a Biacore 3000 instrument (Biacore AB, Uppsala, Sweden). CaM was immobilized covalently on a hydrophilic carboxymethylated dextran matrix sensor chip (Biacore $\mathrm{AB}$ ), with standard amine coupling chemistry [66] at $\mathrm{pH} 3.8$, at a level of $4000 \mathrm{RU}$. Binding of the peptide was tested in $10 \mathrm{mM}$ HEPES $\mathrm{pH} 7.5,150 \mathrm{mM} \mathrm{NaCl}, 4 \mathrm{mM} \mathrm{CaCl}_{2}$ containing $0.005 \%$ P-20 surfactant (Biacore $\mathrm{AB}$ ), at a flow rate of 30 $\mu \mathrm{l} / \mathrm{min}$. Various concentrations of the peptide $(2.5-200$ $\mu \mathrm{M}$ ) were injected in duplicate over both of the flow cells for $3 \mathrm{~min}$, and a 6-min dissociation phase followed each injection. The surfaces were regenerated with a 20-s injection of $10 \mathrm{mM}$ EDTA and another 10-s injection of $20 \mathrm{mM}$ $\mathrm{NaOH}$ at a flow rate of $30 \mu \mathrm{l} / \mathrm{min}$ prior to the next injection cycle. The BIAevaluation software version 3.1 (Biacore $\mathrm{AB}$ ) was used to analyse the data. Bulk effects were subtracted using a reference surface without CaM. Furthermore, a sensorgram of the injection of buffer alone was subtracted from the data. The data were analysed using the various interaction models available in the software, including the mass transfer model. The only model giving a reasonable fit to the data was the conformational change model (see Results).

A control experiment for linked reactions ("heterogeneity test") for the binding reaction was used to analyse the stability of the forming complex as a function of injection time. A $20-\mu \mathrm{M}$ solution of the peptide in the running buffer was injected over the flow cells of the CaM-coated sensor chip at a flow rate of $30 \mu \mathrm{l} / \mathrm{min}$, using different injection times $(1,3$, and $20 \mathrm{~min})$. Each injection was followed by a 15 -min dissociation time. The surface was regenerated and the data were treated as above.

\section{Small-angle $X$-ray scattering \\ SAXS data collection and processing}

Synchrotron X-ray scattering data from solutions of calmodulin in the presence and absence of the MBP peptide were collected at the X33 beamline (DESY, Hamburg) using a MAR345 image plate detector. The scattering patterns of both samples were measured at several solute concentrations $c$, ranging from 5.4 to $140.0 \mathrm{mg} / \mathrm{ml}$, and in the complex samples, a 5 -fold molar excess of the peptide was always present. For the complex, it was calculated, based on the determined $\mathrm{K}_{\mathrm{d}}$ from calorimetry, that more than $99.8 \%$ of total CaM was expected to be in the complex state even at the lowest used concentration. At a sampledetector distance of $2.7 \mathrm{~m}$, the range of momentum transfer $0.1<s<5 \mathrm{~nm}^{-1}$ was covered $(s=4 \pi \sin (\theta) / \lambda$ where $2 \theta$ is the scattering angle and $\lambda=0.15 \mathrm{~nm}$ is the X-ray wavelength). The data were processed using standard procedures by the program package PRIMUS [67]. The forward scattering $I(0)$ and the radii of gyration $R_{g}$ were evaluated using the Guinier approximation [68], assuming that at very small angles $\left(s<1.3 / R_{g}\right)$, the intensity is represented as $I(s)=I(0) \exp \left(-\left(s R_{g}\right)^{2} / 3\right)$. The maximum dimensions $D_{\max }$ were computed using the indirect transform package GNOM [30], which also provides the distance distribution functions $p(r)$.

The increase in the molecular mass (MM) of CaM upon peptide binding was verified by the analysis of the forward scattering value $I(0)$ using the proportion $M M \sim I(0) / c$. In addition, the excluded (Porod) volumes $V_{p}$ of the solutes were also analyzed, calculated as [69]:

$$
V=2 \pi^{2} I(0) / \int_{0}^{\infty} s^{2} I(s) d s
$$

In this calculation, an appropriate constant was subtracted from each data point to force the $s^{4}$ decay of the intensity at higher angles following Porod's law [69] for 
homogeneous particles. For globular proteins, Porod (i.e. hydrated) volumes in $\mathrm{nm}^{3}$ are approximately twice the MMs in kDa.

\section{Ab initio shape determination}

Low resolution $a b$ initio shapes of free and loaded CaM were first reconstructed independently using the program DAMMIN [34]. In a more versatile approach, the ab initio model of the complex was constructed by simultaneous fitting of the scattering from free and loaded CaM by a two-component model using the program MONSA $[34,70]$. The program represents the particle as a collection of $M$ >> 1 densely packed beads inside a sphere with the diameter $D_{\max }$. To describe the overall and internal structure of the complex particle, each bead can be assigned either to the solvent (index $=0$ ) or to one of the components (in our case, index $=1$ corresponds to CaM and index $=2$ to the MBP peptide). The complex between $\mathrm{CaM}$ and the peptide is therefore represented at low resolution by two "phases", and the structure is described by a string of length $M$, containing the phase index for each bead $(0,1$, or 2$)$. Simulated annealing (SA) [71-73] is employed to search starting from a random string for a model composed by interconnected compact phases, which simultaneously fits the shape scattering curves from free CaM and the complex $\left(I_{k}(s), \mathrm{k}=1,2\right)$ to minimize overall discrepancy:

$$
\chi^{2}=\sum_{k} \frac{1}{N_{k}-1} \sum_{j}\left[\frac{I_{k}\left(s_{j}\right)-c_{k} I_{k}^{\text {calc }}\left(s_{j}\right)}{\sigma_{k}\left(s_{j}\right)}\right]^{2}
$$

where the index $k$ runs over the scattering curves, $N_{k}$ are the numbers of experimental points, $c_{k}$ are scaling factors, and $I_{\text {calc }}(s)$ and $\sigma\left(s_{j}\right)$ are the intensities calculated from the subsets of the beads, belonging to the appropriate phases and the experimental errors at the momentum transfer $s_{j}$, respectively.

\section{Molecular modelling}

SASREF [36] was employed for molecular modelling of the complex, using the available atomic model of vertebrate calcium-loaded CaM (PDB entry 1UP5) [74]. SASREF employs SA to minimize the target function $F$ in a form:

$$
F=\chi^{2}+\sum_{i} \alpha_{i} P_{i}
$$

where the first term ensures minimization of the overall discrepancy and the set of penalties $P_{i}$ with their weights $\alpha_{\mathrm{i}}$ formulates various requirements and restrictions to the model (e.g. interconnectivity, contacts absence of overlaps) [36]. The penalty weights for disconnectivity and distance restraints had the default values of 10 . The weight of the overlap penalty was increased (to 100), as the resulting models tend to have some clashes while using the default weight.

The peptide was modelled by modifying the sequence of the homologous peptide from human DRP-1 kinase, as present in the corresponding CaM-peptide complex (PDB entry 1WRZ). To account for possible conformational changes upon peptide binding, CaM was represented by three rigid bodies, namely by the N-terminal lobe, the central helix, and the C-terminal lobe (residues 4-64, 6593, and 94-148, respectively). SASREF positions the four rigid bodies (three CaM portions and the peptide) with respect to each other using SA to form an interconnected assembly without steric clashes, while minimising the discrepancy between the experimental data and the scattering profile from the model of the complex. The latter is calculated based on the pre-computed scattering amplitudes of the subunits in the reference positions and orientations. Scattering from the atomic models was calculated using the program CRYSOL [29]. SASREF allows one to account for contacts between specific residues in the subunits using distance restraints. In the present work, the polypeptide chain compatibility of the entire CaM was ensured by restraining the distances between appropriate terminal residues of three CaM portions to $0.4 \mathrm{~nm}$. Moreover, the information on chemical shift perturbations from the NMR experiment (see NMR section) was also included into SAXS-based molecular modelling by adding the proximity requirement between the peptide and the CaM residues that were observed to be involved in binding the MBP peptide. In brief, a distance restraint of $10 \AA$ was used between the peptide and residues $78,80,85$, or 88 of CaM. A restraint of $7 \AA$ was imposed on the distance between the peptide and CaM residues 130, 137, or 141 and between the peptide and CaM residues 143 or 147 . The restraint terms were not adjusted during minimisation. A discussion on the shape of the restraint functions has been previously published [36].

For the $a b$ initio and rigid body analyses, multiple runs were performed to verify the stability of the solution, and typical 3D reconstructions are presented in the results section. The models generated in 10 independent runs yielded an averaged NSD value of about 1.0 according to the automated superposition program SUPCOMB [75]. Such an NSD value means that the models are indistinguishable at the resolution provided by SAXS. The analysis of common structural features of the models was done using the programs DAMAVER [35] and SUPCOMB. The latter program aligns two arbitrary low or high resolution models represented by ensembles of points by minimizing a dissimilarity measure, NSD. For every point (bead or atom) in the first model, the minimum value among the distances between this point and all points in the second 
model is found, and the same is done for the points in the second model. These distances are added and normalized against the average distances between the neighboring points for the two models. Generally, NSD values close to unity indicate that the two models are similar. The program DAMAVER specifies the most typical model (i.e. that having the lowest average NSD with all the other models of the set of superimposed structures).

The rigid body model and the original data are included in this paper as Additional files 3 and 4, respectively.

\section{Size exclusion chromatography}

Gel filtration chromatography with the ÄKTApurifier system (Pharmacia Biotech) was used to investigate the difference in the behaviour of CaM in the presence and absence of the MBP peptide. A Superdex 75 HR 10/30 column (Amersham Pharmacia Biotech) was equilibrated with $50 \mathrm{mM}$ HEPES buffer pH 7.5, $150 \mathrm{mM} \mathrm{NaCl}, 4 \mathrm{mM}$ $\mathrm{CaCl}_{2}$. The experiments were run at a flow rate of $0.5 \mathrm{ml} /$ min, the injection volumes were $250 \mu$ l, the concentration of CaM was $0.8 \mathrm{mM}$, and the concentration of the peptide was $4 \mathrm{mM}$. SDS-PAGE on a $16.5 \%$ Tris-tricine gel (BioRad) combined with silver staining [76] was used to visualise the peptide and CaM from the fractions.

\section{Nuclear magnetic resonance spectroscopy}

All NMR experiments were carried out on a Bruker DMX500 spectrometer using a $5-\mathrm{mm}$ broadband, $\mathrm{z}$-axis gradient-shielded probe at $298 \mathrm{~K}$. Two-dimensional ${ }^{1} \mathrm{H}-15 \mathrm{~N}$ HSQC spectra were obtained by pulse field gradient selection [77]. The sweep width was $12 \mathrm{ppm}$ in the ${ }^{1} \mathrm{H}$ dimension and $30 \mathrm{ppm}$ in the ${ }^{15} \mathrm{~N}$ dimension, with the ${ }^{1} \mathrm{H}$ carrier set at $500.1324 \mathrm{MHz}$ and the ${ }^{15} \mathrm{~N}$ carrier at 50.6814 $\mathrm{MHz}$. The size of the HSQC spectra was a $1024 \times 1024$ real data matrix with eight scans for each experiment. Proton chemical shifts were referenced to 2,2-dimethyl-2-silapentane-5-sulfonate as 0 ppm. Nitrogen-15 chemical shifts were referenced to liquid $\mathrm{NH}_{3}$.

The sequential assignments for the backbone nuclei of the ${ }^{15} \mathrm{~N} /{ }^{13} \mathrm{C}$-labeled $\mathrm{Ca}^{2+} / \mathrm{CaM}$ were mainly achieved by a set of experiments, CBCA(CO)NNH, CBCANNH, HNCO, and $\mathrm{HN}(\mathrm{CA}) \mathrm{CO}$. Sidechain assignments were obtained using $\mathrm{HBHA}(\mathrm{CO}) \mathrm{NNH}, \mathrm{H}(\mathrm{CCCO}) \mathrm{NNH}, \mathrm{CC}(\mathrm{CO}) \mathrm{NNH}$, and HCCH-TOCSY experiments. The assignments for the protein backbone nuclei of the ${ }^{15} \mathrm{~N}$-labeled $\mathrm{Ca}^{2+} / \mathrm{CaM}-$ MBP peptide complex were achieved by the two-dimensional ${ }^{1} \mathrm{H}-{ }^{15} \mathrm{~N}$ HSQC spectral changes induced by titrations of myelin peptide to the $\mathrm{Ca}^{2+} / \mathrm{CaM}$. NMR spectra were processed on a Silicon Graphics O2 workstation using Bruker XWIN-NMR and Accelrys Felix 2000 software packages.

\section{Abbreviations}

CaM, calmodulin; MBP, myelin basic protein; CD, circular dichroism; ITC, isothermal titration calorimetry; SPR, surface plasmon resonance; SAXS, small-angle X-ray scattering; SA, simulated annealing; CNS, central nervous system; PNS, peripheral nervous system; RU, resonance unit; $\mathrm{NMR}$, nuclear magnetic resonance; MM, molecular mass; NSD, normalised spatial discrepancy

\section{Authors' contributions}

$\mathrm{PK}$ and VM conceived of the study. All authors participated in experiments, data analysis, and writing the paper, and have read and approved of the final draft.

\section{Additional material}

\begin{abstract}
Additional file 1
from CaM-sepharose chromatography. Mass spectroscopic analysis of fractions 2 (2nd wash, top) and 7 (2nd EGTA eluate, bottom) from affinity chromatography of human brain MBP on CaM sepharose. Note the presence of the 17.2- and 18.5-kDa forms of MBP in both fractions.

Click here for file

[http://www.biomedcentral.com/content/supplementary/14726807-8-10-S1.jpeg]
\end{abstract}

\section{Additional file 2}

Conformational change of the C-terminal lobe of CaM upon peptide binding. A stereo Quicktime movie showing the predicted movement occurring in the C-terminal lobe of CaM upon binding the MBP peptide. The conformation of the complex is as obtained by the combined use of our NMR and SAXS data. Colouring as in figure $9 B$.

Click here for file

[http://www.biomedcentral.com/content/supplementary/14726807-8-10-S2.mov]

\section{Additional file 3}

The model refined by SASREF rigid body fitting against the SAXS data, including restraints based on the NMR results.

Click here for file

[http://www.biomedcentral.com/content/supplementary/14726807-8-10-S3.pdb]

\section{Additional file 4}

The measured SAXS data; buffer blank scattering has been subtracted. Click here for file

[http://www.biomedcentral.com/content/supplementary/14726807-8-10-S4.dat]

\section{Acknowledgements}

The authors wish to thank Prof. Rik Wierenga, Prof. Gunter Schneider, and Prof. Ylva Lindqvist for kindly supporting this research and Prof. George Harauz and Dr. Inari Kursula for valuable discussions. Dr. Jenny $G u$ is acknowledged for analysing our sequence with her Wiggle program, Dr. Ulrich Bergmann for helping with mass spectroscopy, and Dr. Tuomo Glumoff for allowing us to use his SAXS beamtime at the EMBL/DESY. We gratefully acknowledge the gift of human brain MBP obtained from Ari Båtsman, Fermlabs, Turku, Finland. This study has been financially supported by 
the Academy of Finland (PK), the Department of Biochemistry, University of Oulu (VM), and the Finnish MS Foundation (VM). MVP and DIS acknowledge support from the Design Study "SAXIER", contract number 0II934.

\section{References}

I. Quarles RH, Farrer RG, Yim SH: Structure and function of myelin, an extended and biochemically modified cell surface membrane. In Cell biology and pathology of myelin: Evolving biological concepts and therapeutic applications Edited by: Juurlink BHJ, Devon RM, Doucette JR, Nazarali AJ, Schreyer DJ, Verge VMK. New York: Plenum Press; 1997: I-I 2.

2. Boggs JM: Myelin basic protein: a multifunctional protein. Cell Mol Life Sci 2006, 63:1945-196I.

3. Harauz G, Ishiyama N, Hill CM, Bates IR, Libich DS, Fares C: Myelin basic protein-diverse conformational states of an intrinsically unstructured protein and its roles in myelin assembly and multiple sclerosis. Micron 2004, 35:503-542.

4. Kamholz J, de Ferra F, Puckett C, Lazzarini R: Identification of three forms of human myelin basic protein by cDNA cloning. Proc Natl Acad Sci USA 1986, 83:4962-4966.

5. Benjamins JA, Morell P: Proteins of myelin and their metabolism. Neurochem Res 1978, 3:137-174.

6. Moscarello MA: Myelin basic protein, the "executive" molecule of the myelin membrane. In Cell biology and pathology of myelin: Evolving biological concepts and therapeutic approaches Edited by: Juurlink BHJ, Devon RM, Doucette JR, Nazarali AJ, Schreyer DJ, Verge VMK. New York: Plenum Press; 1997:13-26.

7. Conlon P, Oksenberg JR, Zhang J, Steinman L: The immunobiology of multiple sclerosis: an autoimmune disease of the centra nervous system. Neurobiol Dis 1999, 6:149-166.

8. Beniac DR, Luckevich MD, Czarnota GJ, Tompkins TA, Ridsdale RA Ottensmeyer FP, Moscarello MA, Harauz G: Three-dimensional structure of myelin basic protein. I. Reconstruction via angular reconstitution of randomly oriented single particles. J Biol Chem 1997, 272:426 I-4268.

9. Ridsdale RA, Beniac DR, Tompkins TA, Moscarello MA, Harauz G: Three-dimensional structure of myelin basic protein. II. Molecular modeling and considerations of predicted structures in multiple sclerosis. J Biol Chem 1997, 272:4269-4275.

10. Haas H, Oliveira CL, Torriani IL, Polverini E, Fasano A, Carlone G, Cavatorta P, Riccio P: Small angle x-ray scattering from lipidbound myelin basic protein in solution. Biophys J 2004 86:455-460.

II. Boggs JM, Rangaraj G: Interaction of lipid-bound myelin basic protein with actin filaments and calmodulin. Biochemistry 2000 , 39:7799-7806.

12. Dobrowolski Z, Osinska H, Mossakowska M, Barylko B: Ca2+-calmodulin-dependent polymerization of actin by myelin basic protein. Eur J Cell Biol 1986, 42:17-26

13. Barylko B, Dobrowolski Z: Ca2+-calmodulin-dependent regulation of F-actin-myelin basic protein interaction. Eur J Cell Biol 1984, 35:327-335.

14. Hill CM, Libich DS, Harauz G: Assembly of tubulin by classic myelin basic protein isoforms and regulation by post-translational modification. Biochemistry 2005, 44: I6672-I 6683.

15. Galiano MR, Andrieux A, Deloulme JC, Bosc C, Schweitzer A, Job D, Hallak ME: Myelin basic protein functions as a microtubule stabilizing protein in differentiated oligodendrocytes. I Neurosci Res 2006, 84:534-54I.

16. Berggard T, Arrigoni G, Olsson O, Fex M, Linse S, James P: I40 mouse brain proteins identified by $\mathrm{Ca2}+$-calmodulin affinity chromatography and tandem mass spectrometry. J Proteome Res 2006, 5:669-687.

17. Grand RJ, Perry SV: The binding of calmodulin to myelin basic protein and histone H2B. Biochem J 1980, 189:227-240.

18. Libich DS, Harauz G: Interactions of the I 8.5-kDa isoform of myelin basic protein with $\mathrm{Ca}(2+)$-calmodulin: in vitro studies using fluorescence microscopy and spectroscopy. Biochem $\mathrm{Cell}$ Biol 2002, 80:395-406.

19. Libich DS, Harauz G: Interactions of the 18.5 kDa isoform of myelin basic protein with $\mathrm{Ca2+-calmodulin:} \mathrm{in} \mathrm{vitro} \mathrm{studies}$ using gel shift assays. Mol Cell Biochem 2002, 241:45-52.

20. Libich DS, Hill CM, Bates IR, Hallett FR, Armstrong S, Siemiarczuk A Harauz G: Interaction of the 18.5-kD isoform of myelin basic protein with $\mathrm{Ca}+$ - calmodulin: effects of deimination assessed by intrinsic Trp fluorescence spectroscopy, dynamic light scattering, and circular dichroism. Protein $\mathrm{Sci}$ 2003, I 2: I507-I52I.

21. Libich DS, Hill CM, Haines JD, Harauz G: Myelin basic protein has multiple calmodulin-binding sites. Biochem Biophys Res Commun 2003, 308:313-319.

22. Polverini E, Boggs JM, Bates IR, Harauz G, Cavatorta P: Electron paramagnetic resonance spectroscopy and molecular modelling of the interaction of myelin basic protein (MBP) with calmodulin (CaM)-diversity and conformational adaptability of MBP CaM-targets. J Struct Biol 2004, I 48:353-369.

23. Zhang Z, Ottens AK, Golden EC, Hayes RL, Wang KKW: Using calmodulin-affinity capture to study the rat brain calmodulin binding proteome and its vulnerability to calpain and caspase proteolysis. Calcium Binding Proteins 2006, I: I 25-I34.

24. Boggs JM, Rangaraj G, Hill CM, Bates IR, Heng YM, Harauz G: Effect of arginine loss in myelin basic protein, as occurs in its deiminated charge isoform, on mediation of actin polymerization and actin binding to a lipid membrane in vitro. Biochemistry 2005, 44:3524-3534

25. Yap KL, Kim J, Truong K, Sherman M, Yuan T, Ikura M: Calmodulin target database. J Struct Funct Genomics 2000, I:8- I4.

26. Andrade MA, Chacon P, Merelo Jl, Moran F: Evaluation of secondary structure of proteins from UV circular dichroism spectra using an unsupervised learning neural network. Protein Eng 1993, 6:383-390.

27. Wintrode PL, Privalov PL: Energetics of target peptide recognition by calmodulin: a calorimetric study. I Mol Biol 1997, 266: $1050-1062$

28. Gestwicki JE, Hsieh HV, Pitner JB: Using receptor conformational change to detect low molecular weight analytes by surface plasmon resonance. Anal Chem 200I, 73:5732-5737.

29. Svergun DI, Barberato C, Koch MHJ: CRYSOL - a program to evaluate $X$-ray solution scattering of biological macromolecules from atomic coordinates. J Appl Crystallogr 1995, 28:768-773.

30. Svergun DI: Determination of the regularization parameter in indirect-transform methods using perceptual criteria. J Appl Crystallogr 1992, 25:495-503.

31. Clapperton JA, Martin SR, Smerdon SJ, Gamblin SJ, Bayley PM: Structure of the complex of calmodulin with the target sequence of calmodulin-dependent protein kinase I: studies of the kinase activation mechanism. Biochemistry 2002, 4I:|4669-14679.

32. Ikura M, Clore GM, Gronenborn AM, Zhu G, Klee CB, Bax A: Solution structure of a calmodulin-target peptide complex by multidimensional NMR. Science 1992, 256:632-638.

33. Meador WE, Means AR, Quiocho FA: Target enzyme recognition by calmodulin: 2.4 A structure of a calmodulin-peptide complex. Science 1992, 257:1251-1255

34. Svergun DI: Restoring low resolution structure of biological macromolecules from solution scattering using simulated annealing. Biophys J 1999, 76:2879-2886.

35. Volkov VV, Svergun DI: Uniqueness of ab initio shape determination in small angle scattering. J Appl Crystallogr 2003 , 36:860-864.

36. Petoukhov MV, Svergun DI: Global rigid body modeling of macromolecular complexes against small-angle scattering data. Biophys J 2005, 89: I237-I250.

37. Baumann N, Pham-Dinh D: Biology of oligodendrocyte and myelin in the mammalian central nervous system. Physiol Rev 200I, 81:87|-927.

38. Campagnoni AT, Macklin WB: Cellular and molecular aspects of myelin protein gene expression. Mol Neurobiol 1988, 2:41-89.

39. Capello E, Voskuhl RR, McFarland HF, Raine CS: Multiple sclerosis: re-expression of a developmental gene in chronic lesions correlates with remyelination. Ann Neurol 1997, 41:797-805.

40. Chin D, Means AR: Calmodulin: a prototypical calcium sensor. Trends Cell Biol 2000, 10:322-328.

4I. Kakiuchi S, Yasuda S, Yamazaki R, Teshima Y, Kanda K, Kakiuchi R, Sobue K: Quantitative determinations of calmodulin in the supernatant and particulate fractions of mammalian tissues. J Biochem (Tokyo) 1982, 92:1041-1048.

42. Klein $\mathrm{P}$, Pawson $\mathrm{T}$, Tyers $\mathrm{M}$ : Mathematical modeling suggests cooperative interactions between a disordered polyvalent ligand and a single receptor site. Curr Biol 2003, I 3:1669-I678. 
43. Kishimoto A, Nishiyama $K$, Nakanishi $H$, Uratsuji $Y$, Nomura $H$, Takeyama $Y$, Nishizuka $Y$ : Studies on the phosphorylation of myelin basic protein by protein kinase $C$ and adenosine $3^{\prime}: 5^{\prime}-$ monophosphate-dependent protein kinase. J Biol Chem 1985, 260: 12492-12499.

44. Kim JK, Mastronardi FG, Wood DD, Lubman DM, Zand R, Moscarello MA: Multiple sclerosis: an important role for post-translational modifications of myelin basic protein in pathogenesis. Mol Cell Proteomics 2003, 2:453-462.

45. Harauz G, Musse AA: A Tale of Two Citrullines-Structural and Functional Aspects of Myelin Basic Protein Deimination in Health and Disease. Neurochem Res 2007, 32:137-I58.

46. Brokx RD, Lopez MM, Vogel HJ, Makhatadze GI: Energetics of target peptide binding by calmodulin reveals different modes of binding. J Biol Chem 200I, 276:|4083-I409I.

47. Tsalkova TN, Privalov PL: Thermodynamic study of domain organization in troponin C and calmodulin. J Mol Biol 1985 , | 81:533-544.

48. Hentschke M, Schulze C, Susens U, Borgmeyer U: Characterization of calmodulin binding to the orphan nuclear receptor Errgamma. Biol Chem 2003, 384:473-482.

49. Kranz JK, Lee EK, Nairn AC, Wand AJ: A direct test of the reductionist approach to structural studies of calmodulin activity: relevance of peptide models of target proteins. J Biol Chem 2002, 277:1635I-16354.

50. Xie L, Bourne PE: Functional coverage of the human genome by existing structures, structural genomics targets, and homology models. PLoS Comput Biol 2005, I:e3I.

5I. Kursula P: Structural properties of proteins specific to the myelin sheath. Amino Acids in press.

52. Vetter SW, Leclerc E: Novel aspects of calmodulin target recognition and activation. Eur J Biochem 2003, 270:404-4I4.

53. Linding R, Jensen LJ, Diella F, Bork P, Gibson TJ, Russell RB: Protein disorder prediction: implications for structural proteomics. Structure 2003, I I:1453-1459.

54. DisEMBL - Intrinsic Protein Disorder Prediction [http:// dis.embl.de]

55. Linding R, Russell RB, Neduva V, Gibson TJ: GlobPlot: Exploring protein sequences for globularity and disorder. Nucleic Acids Res 2003, 31:3701-3708.

56. GLOBPLOT - Intrinsic Protein Disorder, Domain \& Globularity Prediction [http://globplot.embl.de]

57. DRIP-PRED [http://www.sbc.su.se/ maccallr/disorder/]

58. Combet C, Blanchet C, Geourjon C, Deleage G: NPS@: network protein sequence analysis. Trends Biochem Sci 2000, 25:147-150.

59. Network Protein Sequence Analysis [http://npsa-pbil.ibcp.fr]

60. Gu J, Gribskov M, Bourne PE: Wiggle-predicting functionally flexible regions from primary sequence. PLoS Comput Biol 2006 , 2:e90.

61. The Calmodulin Target Database [http://calcium.uhnres.uto ronto.ca/ctdb]

62. Hayashi N, Matsubara M, Takasaki A, Titani K, Taniguchi H: An expression system of rat calmodulin using T7 phage promoter in Escherichia coli. Protein Expr Purif 1998, 1 2:25-28.

63. Maatta JA, Coffey ET, Hermonen JA, Salmi AA, Hinkkanen AE: Detection of myelin basic protein isoforms by organic concentration. Biochem Biophys Res Commun 1997, 238:498-502.

64. Gopalakrishna R, Anderson WB: Ca2+-induced hydrophobic site on calmodulin: application for purification of calmodulin by phenyl-Sepharose affinity chromatography. Biochem Biophys Res Commun 1982, 104:830-836.

65. Pfuhl M, Gautel M, Politou AS, Joseph C, Pastore A: Secondary structure determination by NMR spectroscopy of an immunoglobulin-like domain from the giant muscle protein titin. Biomol NMR 1995, 6:48-58.

66. Gohring W, Sasaki T, Heldin CH, Timpl R: Mapping of the binding of platelet-derived growth factor to distinct domains of the basement membrane proteins BM-40 and perlecan and distinction from the BM-40 collagen-binding epitope. Eur J Biochem 1998, 255:60-66.

67. Konarev PV, Volkov VV, Sokolova AV, Koch MHJ, Svergun DI: PRIMUS - a Windows-PC based system for small-angle scattering data analysis. J Appl Crystallogr 2003, 36: |277-| 282.

68. Guinier A: La diffraction des rayons $\mathbf{X}$ aux tres petits angles; application a l'etude de phenomenes ultramicroscopiques. Ann Phys (Paris) 1939, 12:161-237.
69. Porod G: General theory. In Small Angle X-ray Scattering Edited by: Glatter O, Kratky O. London: Academic Press; | 982:|7-51.

70. Petoukhov MV, Svergun DI: Joint use of small-angle $\mathbf{X}$-ray and neutron scattering to study biological macromolecules in solution. Eur Biophys J 2006, 35:567-576.

7I. Ingber L: Simulated annealing: practice versus theory. Math Computer Modeling 1993, 18:29-57.

72. Kirkpatrick S, Gelatt CDJ, Vecci MP: Optimization by simulated annealing. Science 1983, 220:67I-680.

73. Press WH, Teukolsky SA, Wetterling WT, Flannery BP: Cambridge: University Press; 1992.

74. Rupp B, Marshak DR, Parkin S: Crystallization and preliminary $X$-ray analysis of two new crystal forms of calmodulin. Acta Crystallogr D Biol Crystallogr 1996, 52:4 I I-4 I3.

75. Kozin MB, Svergun DI: Automated matching of high- and lowresolution structural models. J Appl Crystallogr 200I, 34:33-4I.

76. Bloom $\mathrm{H}$, Beier $\mathrm{H}$, Gross $\mathrm{H}$ : Improved silver staining of plant proteins, RNA and DNA in polyacrylamide gels. Electrophoresis 1987, 8:93-99.

77. Grzesiek S, Bax A: The importance of not saturation $\mathbf{H 2 O}$ in protein NMR. Application to sensitivity enhancement and NOE measurements. J Am Chem Soc 1993, I I 5: 12593-12594.

Publish with Bio Med Central and every scientist can read your work free of charge

"BioMed Central will be the most significant development for disseminating the results of biomedical research in our lifetime. "

Sir Paul Nurse, Cancer Research UK

Your research papers will be:

- available free of charge to the entire biomedical community

- peer reviewed and published immediately upon acceptance

- cited in PubMed and archived on PubMed Central

- yours - you keep the copyright
BiolMedcentral 